\title{
A sustainability framework for assessing trade-offs in ecosystem services
}

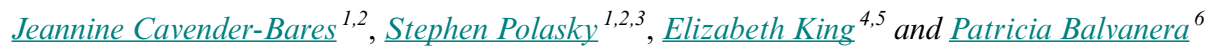

\begin{abstract}
Achieving sustainability, i.e., meeting the needs of current populations without compromising the needs of future generations, is the major challenge facing global society in the 21st century. Navigating the inherent trade-offs between provisioning, regulating, cultural, and supporting ecosystem services, and doing so in a way that does not compromise natural capital needed to provide services in the future, is critical for sustainable resource management. Here we build upon existing literature, primarily from economics and ecology, to present an analytical framework that integrates (1) the ecological mechanisms that underpin ecosystem services, (2) biophysical trade-offs and inherent limits that constrain management options, (3) preferences and values of stakeholders, and (4) explicit analysis of how systems evolve through time to ensure the goal of meeting the needs of future generations. Well-known ecological models define the relationships and trade-offs among services that represents an "efficiency frontier." Well-known methods in economics that combine preferences that define the willingness of stakeholders to trade off ecosystem services on the efficiency frontiers illuminate desirable outcomes that meet human needs. System dynamics show how the system will evolve with consequent impacts on ecosystem services and human well-being and the effects this has on achieving sustainability. Heterogeneity in biophysical constraints, uncertainty, technological advances, and obstacles imposed by societal factors and governance regimes influence potential and realized ecosystem services. Using a set of contrasting scenarios, we illustrate how progress can be made toward sustainability and the important obstacles that must be addressed in doing so. Our framework for analyzing sustainability drawn from economics and ecology is intended to make an integration of concepts from both disciplines accessible to a wider audience.
\end{abstract}

Key Words: dynamics; ecosystem services; efficiency frontier; management constraints; preferences; stakeholders; time lags; trade-offs

\section{INTRODUCTION}

The projected increase in global human population to 9 or 10 billion by mid to late century makes the dual goals of meeting current human needs and sustaining the Earth's natural capital necessary for meeting future human needs both increasingly critical and more difficult. Growth in global human population and per capita consumption are creating unprecedented demands for food, energy, minerals, and other natural resources, and simultaneously placing great pressures on the global environment. For example, the combination of population increase and shift in diet toward more meat has been projected to double demand for food by 2050 (Tilman et al. 2011). Producing food to meet this growing demand will likely require increasing yields through agricultural intensification (Foley et al. 2011) and expanding the amount of agricultural land (Alexandratos and Bruinsma 2012) with consequent changes in nutrient and hydrological cycles, habitats, and climate.

Navigating the trade-offs between provisioning, regulating, cultural, and supporting ecosystem services, as well as maintaining natural capital that is critical to generate future services, is essential for achieving sustainability. Supplying the increasing demand for provisioning services such as food, energy, and minerals often comes at the cost of decreasing the supply of regulating, cultural, or supporting services (Millennium Ecosystem Assessment 2005). Well-known examples include trade-offs between increasing crop yield versus maintaining water quality (Tilman et al. 2002, Zhang et al. 2007), and extraction of timber versus maintaining biodiversity and carbon storage in forests (Putz and Romero 2001, Nelson et al. 2008). Increases in current provisioning services at the cost of regulating and supporting services translate into negative impacts on natural capital important for the supply of ecosystem services in the future. However, sustainability requires leaving to future generations the manufactured, human, social, and natural capital that will allow them to have conditions equivalent to those of the current generation (Arrow et al. 2004).

In this paper we draw from an extensive literature in ecology, economics, and other fields to address issues of trade-offs among ecosystem services in the context of sustainability. We provide a simple integrated framework for the analysis of important societal choices affecting ecosystems and their contribution to human well-being. This framework has four essential components: (1) the ecological mechanisms that underpin ecosystem services, (2) biophysical trade-offs and inherent limits that constrain management options, (3) preferences and values of stakeholders, and (4) explicit analysis of how systems evolve through time.

There is a growing array of tools for analyzing how alternative ecosystem management interventions generate trade-offs in the provision of different ecosystem services (e.g., Raudsepp-Hearne et al. 2010, Kareiva et al. 2011, UK National Ecosystem Assessment 2011, Kline and Mazzotta 2012, Smith et al. 2012, White et al. 2012). Such tools are in high demand for decision making in a range of contexts and spatial scales. These tools are advancing rapidly in sophistication and usefulness. Assessments of trade-offs among services and the implications these trade-offs have for social well-being have relied on projected changes in land use/land cover (e.g., Foley et al. 2005, Nelson et al. 2008, Goldstein et al. 2012, White et al. 2012, Lawler et al. 2014) and combined land-use/land-cover change and climate change (e.g., Bateman et al. 2013). Other work has analyzed management of socialecological systems with potential thresholds in lakes (Scheffer 1997, Carpenter et al. 1999), grasslands (Perrings and Walker 1997, Janssen et al. 2004), coral reefs (Hughes et al. 2003), and energy use and climate change (Keller et al. 2004, Lemoine and Traeger 2014).

${ }^{1}$ Department of Ecology, Evolution and Behavior, University of Minnesota, ${ }^{2}$ Institute on Environment, University of Minnesota, ${ }^{3}$ Department of Applied Economics, University of Minnesota, ${ }^{4}$ Biological Sciences, Odum School of Ecology, University of Georgia, ${ }^{5}$ Warnell School of Forestry and Natural Resources, University of Georgia, ${ }^{6}$ Centro de Investigaciones en Ecosistemas, Universidad Nacional Autónoma de México 
Management of social-ecological systems requires understanding both the biophysical constraints that create trade-offs among ecosystem services and human values that tell us what ecosystem services are preferred by different stakeholders and how the services contribute to their well-being. Major barriers to effective resource planning and management arise because different stakeholder groups hold different preferences for and values about services (Martín-López et al. 2012), and services differ in their spatial or temporal patterns of benefits and costs (Hein et al. 2006, Laterra et al. 2012). A wide variety of analytical tools and approaches are applicable to decisions with multiple objectives (e.g., Keeney and Raiffa 1993), and researchers in several disciplines have assessed how different stakeholders experience and benefit from ecosystem services (Champ et al. 2003, Freeman 2003, Díaz et al. 2011, Chan et al. 2012, MartínLópez et al. 2012). Such assessments can be linked explicitly to spatial information on service supply to show who benefits and who bears costs with changes in the bundle of services. Conceptual frameworks for the systematic assessment of the likelihood of institutional arrangements leading toward sustainability (e.g., Ostrom 2009) and models predicting the outcome based on differences in the organizational power of stakeholder groups (e.g., Scheffer et al. 2000) are also available. In a companion paper, we discuss issues that arise because of conflicting views over what is desirable and institutional impediments to achieving desired ends (E. G. King, J. CavenderBares, T. Mwampamba, P. Balvanera, and S. Polasky, unpublished manuscript).

Work done in economics that is primarily directed to economists is often not read by noneconomists, and the same is true for work in ecology and in other disciplines. Our main purpose in this paper is to present key insights on ecosystem service trade-offs and sustainability that arise in different fields in an integrated and readily accessible fashion to broaden the reach of this work.

\section{CONCEPTUAL FOUNDATIONS}

The current situation in ecosystem services and sustainability science is somewhat analogous to the situation in economics in the 1950s. Rapid advances in economic theory and methods gave rise to a body of new work that became modern welfare economics. Welfare economics combines producer theory, based on production functions that describe what is possible in transforming resources into goods and services (hereafter, services), with consumer theory, based on utility functions that describe the contribution of goods and service to the well-being of an individual (hereafter, utility). In 1957, Francis Bator set out to provide "a complete and concise treatment of the ... 'new welfare economics", (Bator 1957:22). In his article, titled "The simple analytics of welfare maximization," he used logical arguments based on first principles and graphical analysis. Bator's article made the advances in welfare economics more broadly accessible.

Much of what has been developed in welfare economics is also broadly applicable to ecosystem services and sustainability. When applied to the production of services in an economy, the simple analytics of welfare economics can be used to establish a "production possibility frontier" that defines the maximum feasible combinations of services that can be produced with the resources available. Combining the production possibility frontier with the utility function of individuals in society defines a "utility possibility frontier" showing maximum achievable welfare combinations for individuals in society. The utility possibility frontier describes the conditions for both production and consumption necessary to achieve a Pareto optimal outcome, defined as an outcome in which it is not possible to make any one person better off without simultaneously making someone else worse off.

The production possibility frontier can be applied to provision of ecosystem services that depend on natural capital and ecosystem processes, as well as other forms of capital, human labor, and other inputs that welfare economics typically incorporates. For example, Polasky et al. (2008) used spatially explicit analysis of land-use decisions to find choices that achieved maximal species conservation for a given value of marketed commodities and vice versa. The production frontier framework has been utilized by others (e.g., Nelson et al. 2008, Kline and Mazzotta 2012, White et al. 2012) to examine trade-offs between different types of ecosystem services. One advantage of this approach is that the model is not constrained to represent productivity for each service in terms of the common metric of money, but can directly show trade-offs between different services measured in their own terms. For example, the species conservation objective was reported in terms of the number of species likely to persist on the landscape rather than attempting to quantify species conservation in monetary terms (Polasky et al. 2008).

Welfare economics is also relevant for ecosystem services and sustainability because it brings in human values to judge which alternatives are preferred because they make people better off. Combining information about the value of services along with the production possibility frontier can show what alternative management approach yields the greatest net benefits. However, there may be a great deal of uncertainty underlying understanding of both the production frontier and the values, so that a robust or resilient alternative may be preferable to one that maximizes a particular realization of the frontier and values (e.g., Lempert 2006, Polasky et al. 2011, Iverson and Perrings 2012).

Much of welfare economics, including the synthesis of Bator (1957), is done in a static context that does not describe the evolution of the ecosystem, the economy, or human well-being through time. More recent analyses that build from a welfare economic framework have explicitly incorporated economic dynamics to factor in considerations of what services can be provided in the future as a function of the amounts of manufactured, human, social, and natural capital that the current generation leaves for future generations (Hamilton and Clemens 1999, Dasgupta and Mäler 2000, Heal 2000, Arrow et al. 2004, Arrow et al. 2012). Work on the dynamics of resource use and sustainability has deep roots, including an outpouring of seminal papers in the late 1960s and early 1970s at the time of the rise of the environmental movement and concerns about resource scarcity (Krutilla 1967, Arrow and Fisher 1974, Dasgupta and Heal 1974, Solow 1974, Stiglitz 1974, Clark 1976). To be truly relevant for sustainability, an approach must incorporate explicit analysis of system dynamics to describe the evolution of the social-ecological system over time (cf. Scheffer and Carpenter 2003, Bennett et al. 2005). Otherwise, it is difficult to say whether natural capital for meeting human needs will ultimately be compromised following a particular management decision. 
We present a framework that illustrates the feasible combinations of ecosystem service supply and their trade-offs, and allows direct visualization of the consequences of different preferences held by stakeholders. The framework can also be used to explore how these trade-offs change across spatial or temporal scales, or identify the factors that underlie the discrepancies in objectives among groups and governance systems, which impede sustainability transitions (discussed in greater depth in E. G. King, J. Cavender-Bares, T. Mwampamba, P. Balvanera, and S. Polasky, unpublished manuscript).

\section{A FRAMEWORK TO ANALYZE ECOSYSTEM SERVICE TRADE-OFFS}

Similar to Bator's 1957 article, "The simple analytics of welfare maximization," which sought to provide a coherent unified treatment of welfare economics that was widely accessible, we sought to provide a coherent unified and clear treatment of ecosystem service trade-offs in the context of sustainability. We did so in a series of steps that (1) defined the biophysical constraints of the system in the form of an efficiency frontier, (2) combined the values of stakeholders and the efficiency frontier, (3) examined temporal lags and intergenerational inequalities, and (4) incorporated thresholds and nonlinear system dynamics. In another study, we examined some of the constraints to reaching efficient outcomes that result from shifting priorities across stakeholder groups, contexts, and scales (E. G. King, J. CavenderBares, T. Mwampamba, P. Balvanera, and S. Polasky, unpublished manuscript).

We used well-known ecological models to define the relationships and trade-offs in two dimensions between two different kinds of services provided by ecosystems, with services being defined as desirable objectives for society, such as habitat provision for populations of species that people care about, filtration of nutrients to provide clean water, and food production. Two dimensions are easiest to visualize but the concepts apply to tradeoffs in multiple dimensions as well. The ecological models, described mathematically in Appendix 1 with $\mathrm{R}$ code shown in Appendix 2, provide representations of steady-state solutions for the biophysical constraints between two services and define a sustainable efficiency frontier based on established ecological principles. We then superimposed preference functions to represent desired outcomes in ecosystem services based on human values. This generated a diagram of the biophysically defined efficiency frontier, overlain with sets of utility isoclines that represent the preferences of different stakeholders. The final step was to take explicit account of system dynamics and show how the system will evolve, with consequent impacts on ecosystem services and human well-being. This step is the most challenging but presents a critical area for future progress.

\section{Biophysical constraints and the efficiency frontier}

We began with a scenario of an ecological system from which two services were generated from a given land area. The biophysical constraints that limited the production of the two services were dependent on both the specific climatic, historical, and resource context of the land area and on the growth or replenishment rate of natural capital stocks. Harvesting some form of ecological productivity such as agricultural crops or timber was done at the expense of biodiversity or water quality. If harvesting was fully maximized, that was expected to negatively impact biodiversity and/or ecosystem biomass by reducing either the biota or the availability of habitat and water quality because of runoff from agricultural fertilizer addition. Three different ecological models from first principles can be used to determine the relationships between the two services. The first and simplest model captures the dependence of natural capital stocks on land area. The second examines the consequences for water quality and agricultural production of terrestrial nutrient storage and water-filtering services when nutrients are applied to crops. The third examines dynamics of cattle herbivores and vegetation biomass in pastoral grassland systems.

In the first example, there is a trade-off between biodiversity or species richness $(\mathrm{S})$ that can be sustained from land area in natural habitat $\left(\mathrm{A}_{\mathrm{H}}\right)$, and agricultural production $(\mathrm{P})$ from land area dedicated to crops $\left(\mathrm{A}_{\mathrm{C}}\right)$. Figure 1 shows two contrasting biophysical contexts: one in which comparatively high agricultural productivity can be achieved but only comparatively low biodiversity, such as the corn belt of the U.S. Midwest. In the other case, comparatively high biodiversity can be sustained but only comparatively low agricultural productivity, such as in highly diverse parts of the tropics with low soil fertility. The conceptual basis for this trade-off is grounded in empirical relationships between habitat area and species richness, originally harnessed in the development of the theory of island biogeography (MacArthur and Wilson 1967); equations are given in Appendix 1, Example 1. The diminishing returns of the species-area curve relationship generate the concave efficiency frontier depicted in Figure 1. The efficiency frontier represents the maximum obtainable combinations of agricultural production and biodiversity from the ecosystem. It represents the biophysical constraints of a particular system in its specific context. The slope of the frontier shows the marginal cost of an additional unit of agricultural production in terms of loss of species diversity. Landscape heterogeneity can also give rise to a concave shape of the efficiency frontier as land is allocated toward production of the service for which it has a comparative advantage (Polasky et al. 2008).

For simplicity, we presented the links between food production and biodiversity conservation as being well understood. In reality, a range of services, e.g., carbon sequestration, maintenance of soil fertility, regulation of pests, and regulation of soil erosion, that operate at different spatial scales may complicate estimation of efficiency frontiers. In fact, assessing the key trade-offs within a variety of land-use conditions and within different societal and biophysical conditions remains an important topic of research (Carpenter et al. 2009, Carpenter et al. 2012). Although an increasing array of tools are available for assessing ecosystem services in the field (de Groot et al. 2010) to model their explicit spatial patterns (Kareiva 2011, Raudsepp-Hearne et al. 2010), the thematic, temporal, and spatial coverage of these initiatives is still limited (Seppelt et al. 2011). Even when data are available on the functions that underpin service provision, it may be difficult to predict the actual delivery of services or the benefits to society. In addition, very few assessments take into account system dynamics and how changes in the system will likely impact the ability of the system to provide services in the future.

Combining the values of stakeholders and the efficiency frontier The efficiency frontier provides information on the combinations of services that are possible, but the optimal choice among these combinations depends on what services stakeholders value most. 
Fig. 1. Building blocks of the framework. (A) Ecosystem service trade-offs result from biophysical constraints that define the efficiency frontier. This example uses a simple land-use model that incorporates species-area relationships (MacArthur and Wilson 1967) to define trade-offs between biodiversity and agricultural production (equations are given in Appendix 1 and $\mathrm{R}$ code is provided in Appendix 2). The curves represent the steady-state number of species that can be sustained given the fraction of land area devoted to habitat vs. crop production. Biophysical constraints vary with context. For example, areas of the Amazon basin (blue curve) have the potential to support high species diversity but only modest agricultural productivity due to relatively low soil fertility: once the forest is cleared nutrient availability declines rapidly. In contrast, the US Midwestern corn belt (black curve) can support high agricultural productivity but comparatively low biodiversity, given its fertile soils but colder climate. (B) Human preferences for ecosystem services. Indifference curves represent preference orderings or well-being scores of two different stakeholders, farmers (blue curves) and environmentalists (red curves) for all combinations of ecosystem services (biodiversity and agricultural productivity). For each stakeholder group, lines of increasing utility are shown from highest to lowest utility (UE1 - UE4 for environmentalists and UF1 - UF4 for farmers). (C) The points where the efficiency frontier intersects with the indifference curves of the highest utility (UF3 or UE3) identifies the combinations of ecosystem benefits that contribute maximally to a stakeholder's well-being. Utility curves above the efficiency frontier (UF4 or UE4) represent benefits that exceed biophysical constraints and are not sustainable. Highest possible benefits for environmentalists (BE) are achieved by a high biodiversity value at the expense of lower agricultural production, while for farmers, higher agricultural production at the expense of lower biodiversity achieves the highest possible benefit (BF). Depending on power relations between these hypothetical stakeholders, the management outcome may be driven closer to BE or BF.

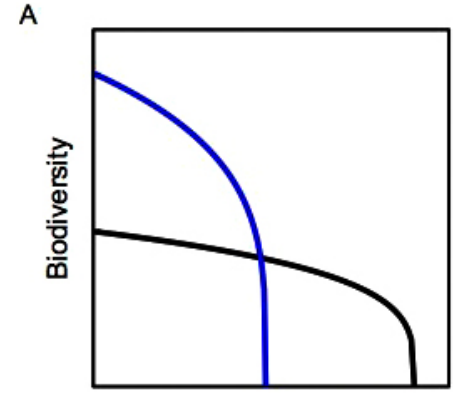

Agricultural Productivity

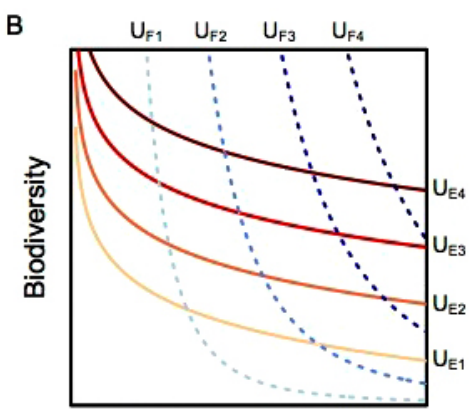

Agricultural Productivity

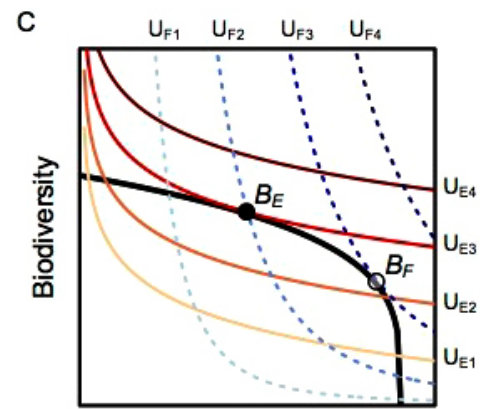

Agricultural Productivity
The human values, ethics, and choices that determine what is preferred vary among stakeholders within and across cultural and institutional settings, and with spatial and temporal scale. The utility function for a given stakeholder summarizes the preferences over combinations of services, i.e., rankings of which bundles of services are preferred to which other bundles of services. Utility isoclines show all combinations of services that produce the same utility, i.e., which are viewed as equivalent in ranking (see Fig. 1B). For example, although farmers (F) would require a large increase in biodiversity to forsake some agricultural production, environmentalists $(\mathrm{E})$ would require a large increase in agricultural production to be willing to lose even a little biodiversity. The utility isocline captures the trade-offs between conservation objectives, measured in terms of biodiversity, and agricultural production that provide equal benefits, i.e., constant utility. Such isoclines can be drawn for different levels of utility.

To assess which combinations of services are most likely to suit the preferences of multiple stakeholders, we superimposed the utility isoclines on the efficiency frontiers (Fig. 1C). Superimposition allows for the identification of feasible combinations of services that provide the most desirable possible outcome for stakeholders. In this case, the most desirable outcome for farmers differed substantially from the most desirable outcome for environmentalists.
Stakeholders' values can be assessed using observations on choices actually made, i.e., revealed preference, or surveys that ask about hypothetical choices, i.e., stated preference (Champ et al. 2003, Freeman 2003). Economists have developed a number of techniques for gathering information about preferences of different stakeholders and the trade-offs they are willing to make that are applicable to ecosystem services (National Research Council 2005). Other social science disciplines also have methods to elicit information about the preferences of different stakeholders through the use of semistructured to open interviews (Castillo et al. 2005, Martín-López et al. 2012). The relative preferences can be ranked through a variety of narrative, deliberative, and participative methods that can range from coarse overviews to very fine resolution information about preferences (Chan et al. 2012).

\section{Temporal lags and intergenerational inequities}

The prior two sections presented the basic building blocks related to efficiency frontiers and the preferences of stakeholders in a static analysis that did not explicitly incorporate time, i.e., system dynamics. But temporal concerns are at the heart of sustainability aimed at securing the well-being of future generations.

Some options that improve the well-being of future generations come at the cost of reducing short-term well-being of the current 
generation. For example, rebuilding fish stocks for long-term health of the fishing industry can require reducing or shutting down harvest for a period of time with an immediate burden on fishermen. Intergenerational inequities are also highlighted by climate change. For future generations to avoid the worst potential consequences of climate change, the current generation must make costly changes in energy consumption and/or give up benefits of fossil fuel use.

We illustrated the problem of temporal lags between benefits and costs by returning to our first example of the trade-off between species diversity and agricultural productivity, using a scenario in which land is taken out of agricultural production to allow greater biodiversity conservation (Fig. 2A). Conversion of agricultural land to maximize biodiversity requires numerous ecological changes, succession, and time for colonization (Chazdon 2008). As a consequence, in the short-term $\left(\mathrm{t}_{1}\right)$, welfare declines as agricultural production declines but the biodiversity benefits are not yet realized. Only after a potentially considerable time $\operatorname{lag}\left(\mathrm{t}_{2}-\right.$ $\mathrm{t}_{0}$ ) do biodiversity and its associated ecosystem services recover, allowing higher welfare to be achieved than at the start (Fig. 2B).

Fig. 2. Progress toward desired management outcomes may be impeded by short-term declines in welfare that arise prior to when the long-term ecosystem benefits can be realized. For example, shifting land management from agricultural production to biodiversity conservation has a delayed effect. (A) Benefits of ecosystem services are initially moderate $\left(B_{t 0}\right)$, as indicated by where the second utility curve $\left(\mathrm{U}_{2}\right)$ intersections the efficiency frontier. As agricultural production declines net benefits also decline $\left(\mathrm{B}_{\mathrm{t} 1}\right)$. After land has been recolonized, higher biodiversity levels are finally achieved and overall ecosystem benefits are higher $\left(\mathrm{B}_{\mathrm{t} 2}\right)$ than at the outset. (B) The anticipated decline in ecosystem service benefits from $t_{0}$ to $t_{1}$ (indicated by the drop from $\mathrm{U}_{2}$ to $\mathrm{U}_{3}$ ) is more than offset by the increase in those benefits at $t_{2}$, (rise from $U_{3}$ to $U_{1}$ ) but the losses and benefits are likely to be realized by different generations.

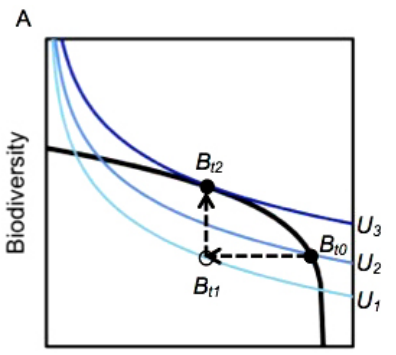

Agricultural Productivity

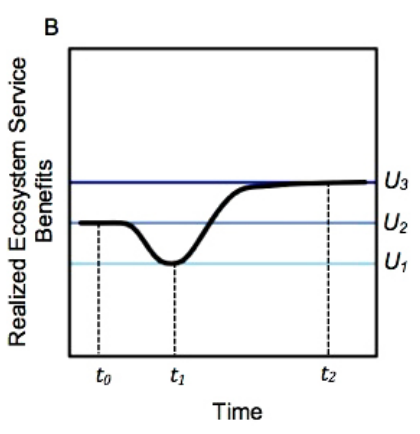

A high rate of discount may prevent society from choosing to make short-term sacrifices for long-term gains. If discounting accurately reflects societal preferences about benefits realized at different times, then the choice not to invest for future benefits is akin to the situations of farmers vis-ô-vis environmentalists in which the farmers have the power to choose a point on the efficiency frontier that favors their interests. However, some have argued that market discount rates would be unlikely to accurately reflect societal preferences, making it inappropriate to apply conventional market discount rates to intergenerational societal decisions affecting sustainability (Sen 1967). Even among economists there are lively debates about the proper role of discounting applied to climate change and other issues that affect different generations (e.g., Nordhaus 2007, Stern and Taylor 2007).

\section{Thresholds and nonlinear system dynamics}

One of the most important features of social-ecological systems is complex dynamics, which contrasts with the simple relationships previously described. For example, consider an agricultural region in which agricultural productivity can be increased through the application of fertilizer, but at the cost of decreasing water quality, which is related to ecosystem services such as providing clean drinking water, recreation, and the maintenance of freshwater biodiversity. The influence of nutrients on algal growth and turbidity in shallow freshwater lakes is well established (e.g., Scheffer 1990, Scheffer et al. 1993, Carpenter et al. 1999). We applied these models to consider tradeoffs in agricultural productivity on land and water quality of neighboring lakes. (See equations in Appendix 1, Example 2; R code is in Appendix 2.) We also considered the role of technology and management practices, which can result in shifts in the efficiency frontier.

Application of fertilizer can increase crop yield, but the function relating fertilizer to yield depends in part on the spatial and temporal precision of fertilizer application. For example, timing fertilizer addition to coincide with early summer crop growth has been shown in many cases to increase the efficiency of nutrient use and crop productivity (Tran et al. 1997, Ma et al. 2003, Scharf and Lory 2009; Fig. 3A).

Nutrient concentrations in the water ultimately depend on levels of nutrient addition to crops and on uptake of the terrestrial system (Carpenter et al. 1999). The extent to which applied nutrients are stored by the terrestrial ecosystem (Fig. 3B) or leaked into neighboring shallow water bodies (Fig. 3C) depends on the efficacy of plant uptake, soil adsorption, and land-use management. Shifts in human land-management practices, such as inclusion of riparian buffer strips and cover crops, are known to increase ecosystem nutrient storage and reduce nutrient runoff (Gilliam 1994, Lowrance et al. 1997, Anbumozhi et al. 2005, Smukler et al. 2012), as illustrated in Figures 3B and 3C.

Water quality in shallow lakes is negatively related to the growth of algae that cause turbidity (Keeler et al. 2012). Increased amount of nutrients in waterways cause algal growth, but the relationship is complex because of feedbacks between algae and aquatic plants, which also use nutrients. Once algal populations rise to a certain level, they make the water sufficiently turbid so that aquatic plants cannot survive, freeing more nutrients for algal growth. Without aquatic plants, algal populations can persist at high levels even with lower levels of nutrient inputs (Scheffer 1990, Scheffer et al. 1993). The trade-off between water quality and crop production resulting from these relationships is highly nonlinear (Fig. 3E). Thresholds exist, beyond which increases in agricultural production because of added fertilizer lead to rapid declines in water quality.

An insight that can be readily perceived from examining ecosystem services described by these ecological relationships is that management practices and technology can change what is possible to achieve in terms of ecosystem service provision from 
Fig. 3. Management practices can shift the efficiency frontier, shown here in terms of trade-offs between agricultural production, on the one hand, and ecosystem nutrient storage and filtration services that affect water quality, on the other. Non-linear trade-offs between water quality and agricultural production are derived from simple relationships between crop yield and nutrient amount, as well as dynamic models of algal growth in response to nutrient run-off based on Scheffer et al 1993. Equations for all of the relationships in A-E are in Appendix 1; R code is in Appendix 2. (A) Crop production increases with increased application of nutrients (black line); increasing the spatial and temporal precision of fertilizer application leads to greater crop production for the same amount of fertilizer input (red line). (B) Crop and ecosystem vegetation takes up some fraction of the applied nutrients (ecosystem storage) before these nutrients can run off into surface waters. Improving management through riparian buffer strips and cover crops, for example, can lead to increased ecosystem storage of excess nutrients (blue line). (C) Nutrients not absorbed by the crops or ecosystem vegetation will run off into surface waters. Improved management (blue line) as in B will reduce runoff for the same amount of fertilizer applied per unit area. (D) Algal growth is dependent on nutrient runoff from the land into the water that drives the water nutrient concentration, but is also affected by growth of aquatic plants. (E) The efficiency frontier is defined by the non-linear relationship between crop yield and water quality emerging from the above relationships. Increased precision and temporal efficiency in nutrient addition (red line) or improved ecosystem management practices, such as riparian buffers (blue line) shift the efficiency frontier to the right, such that higher water quality is achieved for the same agricultural production. (F) Variability and uncertainty in biophysical constraints make managing for optimal outcomes challenging. The gray and black lines indicate contrasting estimates of the efficiency frontier based on uncertainty and variability in system factors (e.g., efficacy of management practices, climate) that influence productivity and water quality. Indifference curves (light, medium and dark blue dashed lines of increasing utility, U1-U3) are shown for land managers indicating a preference for maximizing agriculture productivity over water quality. If management is targeted to the most optimistic envelope of the efficiency frontier in a manner that maximizes utility (shown by the circle at the intersection of the outer gray efficiency frontier and the highest utility curve), the risk of overfertilizing (or over overexploiting a system, more generally) and dropping to a lower utility level is quite high (indicated by the dashed arrow).

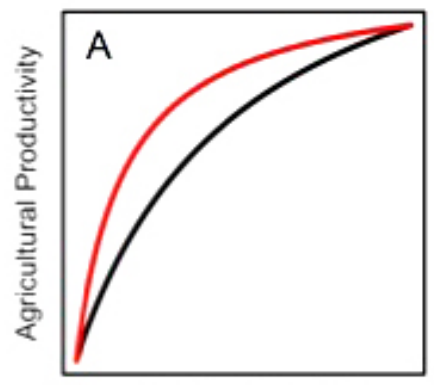

Nutrients Applied

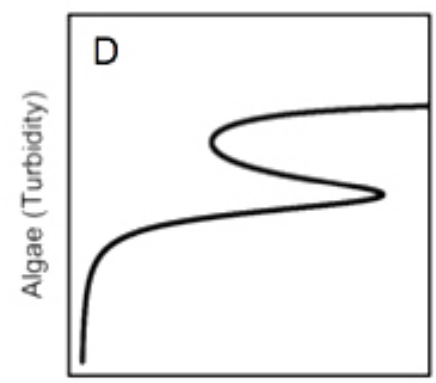

Water Nutrient Concentration

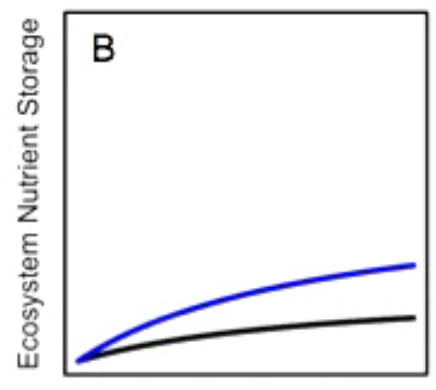

Nutrients Applied

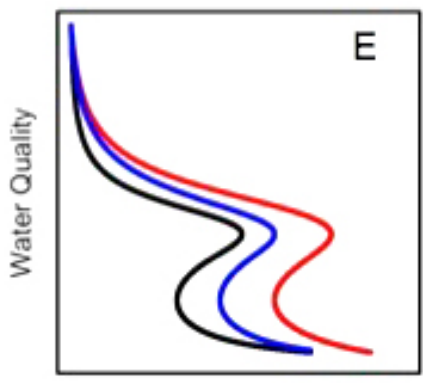

Agricultural Productivity

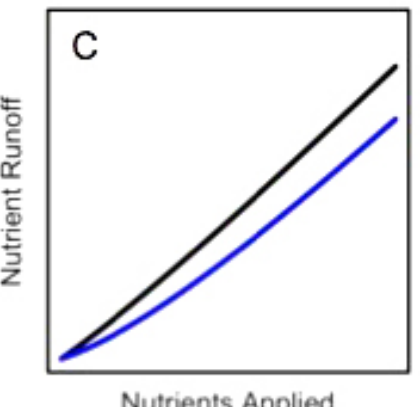

Nutrients Applied

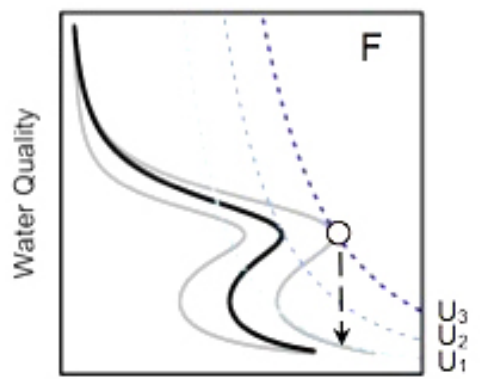

Agricultural Productivity the system. Enhanced precision in the timing of nutrient addition leads to greater crop yield for the same amount of nutrient addition. Buffer strips and cover crops absorb excess nutrients and reduce leakage of fertilizer into waterways. Better management practices thus shift the trade-off curve to the right, increasing agricultural productivity while maintaining or enhancing the ecosystem services that contribute to clean water.

Variability in systems due to weather, pest outbreaks, or other disturbances and uncertainty about the location of potential 
Fig. 4. Complex system dynamics create challenges for sustainable management. (A) Interdependent dynamic components can create unstable and highly fluctuating systems. In this example, a trade-off surface between the regulating ecosystem service, ecosystem biomass, and the provisioning service, cattle density is derived from vegetation growth and cattle consumption of vegetation based on equations from May 1977. At steady state, ecosystem biomass (B) will vary with cattle density (D). Stable equilibrium points are shown by the thick black line. If cattle density is regulated by ecosystem biomass its dynamics can also be described within the system. In one scenario, at steady-state there is a constant biomass at which cattle density will not grow or decline. Arrows indicate the biophysical tendencies when the system tends toward steady state. The dynamics of the system depend on the starting point and are indicated by the vectors indicating where ecosystem biomass or cattle density will be increasing or decreasing towards equilibrium. (B) Vegetation biomass and cattle density are shown through time. In this scenario, highly unstable dynamics can result in which the system oscillates between high and low biomass. (C) In a second scenario, cattle population density is regulated differently than in the first scenario. Cattle density is basically logistic with growth regulated by density and food (ecosystem biomass). (D) The system dynamics are such that ecosystem biomass and cattle population size do not fluctuate; rather, after initial rapid growth of both, if the cattle population continues to increase beyond a threshold, the vegetation biomass crashes and both reach very low equilibrium levels. Restoring higher biomass values would require removing cattle to an extremely low level potentially creating a poverty trap. Equations are provided in Appendix 1 and R code in Appendix 2.

A

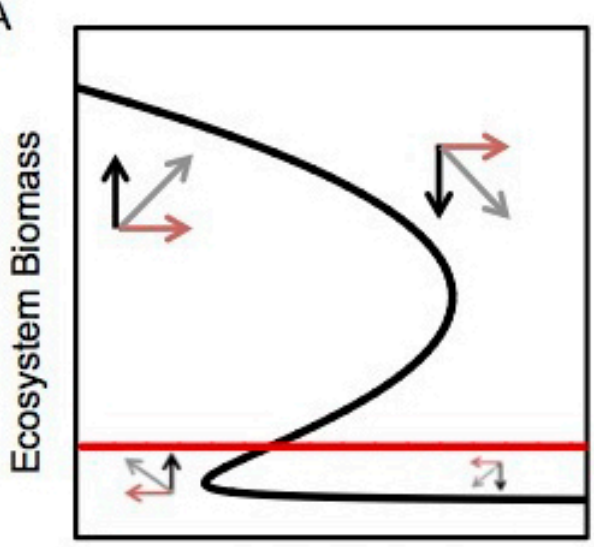

Cattle Density

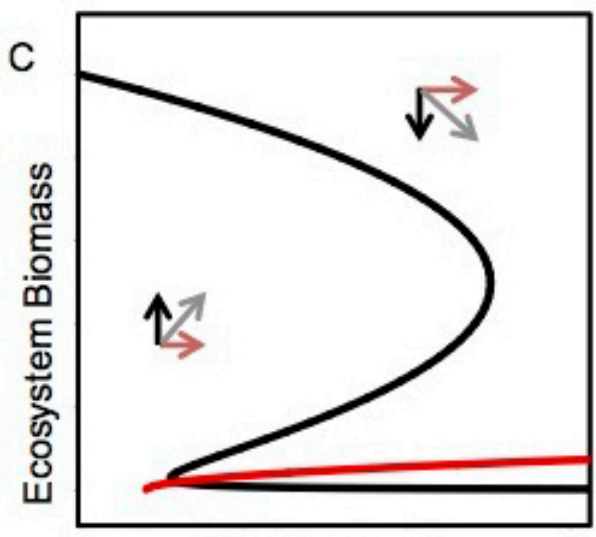

Cattle Density
B

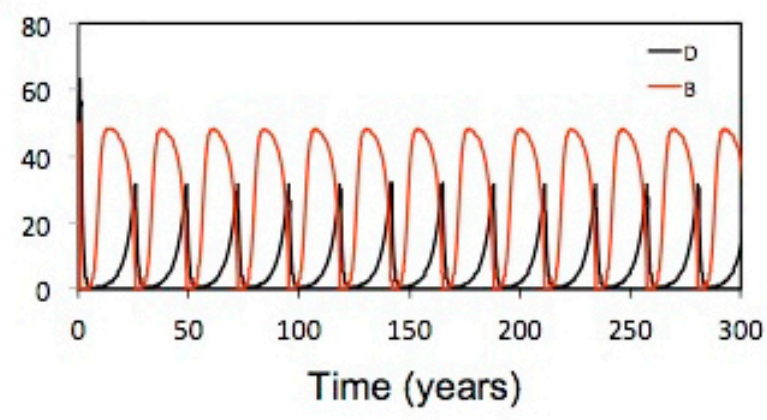

D

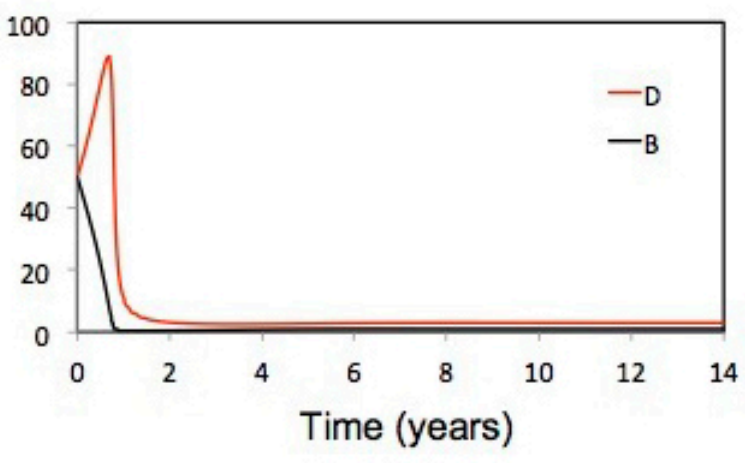

thresholds make managing for optimal outcomes challenging. Trying to maximize benefits assuming the most optimistic envelope of the efficiency frontier (right-most gray curve; Fig. 3F) could result in overfertilizing or, more generally, overexploiting a system and crossing a threshold that would result in dropping to a lower level of benefits. This risk is reduced for a more conservative envelope of the efficiency frontier (left-most gray curve).

Thresholds and nonlinear dynamics pose difficult problems for sustainable management of social-ecological systems. Consider 
the case of a pastoral Maasai community in Kenya, where high variability in environmental conditions causes instability, challenging efforts to manage ecosystem services sustainably. In pastoral systems such as this one, a trade-off exists between the ability of the system to support cattle for meat or milk production and the ability to support ecosystem biomass and primary productivity (May 1977; Appendix 1, Example 3; $\mathrm{R}$ code is provided in Appendix 2). Population growth of cattle is regulated by ecosystem biomass, which is consumed as a function of cattle density according to various possible mechanisms. Two of these mechanisms are shown (Fig. 4). The steady-state population density of cattle is constant with increasing ecosystem biomass in the first case (red line, Fig. 4A) and increases with increasing ecosystem biomass in the second (red line, Fig. 4B). The dynamics of the system are thus driven by the interacting tendencies of the biomass growth and the cattle population growth, which may result in fluctuating ecosystem functions/ services or very low services, as in the examples shown. If the system is well understood, which arguably it has been by traditional populations, the cattle density that results in a sustainable level of services can be determined. Management practices, including intentional nomadic movement of human and cattle populations or intentional movement of cattle outside the focal region, can adjust in a manner that prevents large-scale fluctuations. When human population pressure becomes too great or pastoralist mobility is restricted (Niamir-Fuller 1998), traditional management options may no longer permit system recovery from low levels of ecosystem provisioning as they once did, leading to worsening human and environmental conditions (Roe et al. 2011). We acknowledge that the simple models presented here are equilibrial, but such systems do not necessarily reach equilibrium, posing challenges to our ability to predict outcomes (Vetter 2005).

\section{Challenges and prospects}

Modeling nonlinear dynamics to predict the different trajectories that social-ecological systems can undergo based on the biophysical drivers and management decisions remains highly challenging. The dynamics of many systems are still far from well understood. Although important advances have been made in assessing the dynamics of these kinds of systems (e.g., Anderies et al. 2004), integration of dynamics with the other elements included in the sustainability framework reviewed here remains a critical challenge.

Our sustainability framework emphasizes the ecological processes underlying the production of ecosystem services that contribute to human well-being. This emphasis complements the work of economists on "inclusive wealth" (Hamilton and Clemens 1999, Dasgupta and Mäler 2000, Heal 2000, Arrow et al. 2004, 2012). Inclusive wealth is a measure of the value of all capital assets, i.e., manufactured, human, social, and natural capital, with value reflecting the contribution of the asset to providing benefits both now and in the future. To be sustainable, inclusive wealth should be nondeclining, so that future generations have bundles of assets that are of equal or greater value than the value of current assets. The advantage of the inclusive wealth approach is that it offers a clear and simple criterion for sustainability with a comprehensive and global scope (Cavender-Bares et al. 2013). In its current form, however, it does not include analysis of the underlying ecological mechanisms for how natural capital contributes to the provision of ecosystem services that contribute to human well-being; how biophysical conditions change across space, through time, and with management; how inherent trade-offs among services emerge; and how the values of services change among stakeholders (Stiglitz et al. 2009). We emphasize a focus on the ecological mechanisms, complexities, and inherent trade-offs in the production of ecosystem services that may offer guidance in decision making about such trade-offs. We also discuss how changes across biophysical and societal context influence the trade-offs among services. By differentiating among stakeholders with differential preferences and values, we show the complexities inherent to the search for achieving sustainability. Although our illustrations are presently limited in scope, incorporating ecological processes in the welfare-economics approach of inclusive wealth offers considerable potential for making progress on analysis of sustainability. Our approach considers ecological mechanisms, complexities, and uncertainties, and aims at merging other ongoing efforts (Ostrom 2009, Stiglitz et al. 2009) to include greater depth on social, economic, and political dimensions (See E. G. King, J. Cavender-Bares, T. Mwampamba, P. Balvanera, and S. Polasky, unpublished manuscript).

The process of developing a study in the context of the sustainability framework as we have outlined it is a valuable exercise (cf. Ewing and Runck 2015, Grossman 2015, Mastrangelo and Laterra 2015; P. Balvanera, F. Mora, A. Castillo, and J. Trilleras, unpublished manuscript, M. ). It untangles the known from the perceived, makes transparent disparate viewpoints and underlying assumptions of stakeholders, and clarifies the information base that stakeholders rely on for informing themselves about the system. Moreover, it identifies the data gaps so that stakeholders can make more informed decisions about the most appropriate intervention for an area, given social and biophysical constraints (Grossman 2015; P. Balvanera, F. Mora, A. Castillo, and J. Trilleras, unpublished manuscript). The process itself, however, may be more valuable than any immediate outcome of the analysis. As such, the framework has the potential to contribute to a participatory approach (E. G. King, J. Cavender-Bares, T. Mwampamba, P. Balvanera, and S. Polasky, unpublished manuscript) that builds trust, common ground, and the working environment needed to address ecological problems in a way that can secure long-term commitment to resolving them, which is a necessary building block for sustainability. Ultimately, an integrated social-ecological analysis of the trade-offs among ecosystem services and their dynamics through time is necessary to assess how close or far we are from attaining sustainability.

\section{CONCLUSIONS}

Assessing progress toward or away from sustainability is crucial to tackle the most urgent challenges of our time. Bator (1957) provided a clear exposition of the important elements of welfare economics. Taking inspiration from this work, we have similarly tried to provide a clear exposition of the important elements from ecology and economics for understanding trade-offs among ecosystem services in the context of social-ecological system sustainability. We emphasize consideration of the ecological processes that underlie the production of services and the temporal lags and dynamics of social-ecological systems. The ecological examples we used to illustrate the framework were drawn from well-known relationships and used relatively simple mathematical models. These simple examples highlight the often quite complex relationships among ecosystem services. These 
models also demonstrate how trade-offs differ by location depending on environmental conditions and how the location and shape of the efficiency frontier can change in response to technological change. These relationships can be estimated from empirical data, as other investigators contributing to this Special Feature have attempted to do, allowing the framework to be applied to a variety of case studies with different levels of understanding of the social-ecological system and its dynamics. Further, ecosystem service supply and delivery can be predicted under future scenarios for ecosystem service provision by using qualitative or quantitative approaches (Parker et al. 2003, Nelson et al. 2009, Lawler et al. 2014) and incorporating stakeholder views (Goldstein et al. 2012).

Combining stakeholders' perspectives with information about the efficiency frontier can help to clarify how preferences and power relations can shift outcomes to different points on the frontier, some of which may be inequitable outcomes. The difficulties that arise from contrasting values and management priorities in different contexts and scales are treated in greater depth in the paper by King et al. (2014). Consideration of the temporal dimensions of, as well as the uncertainties about, biophysical relationships and values poses difficult challenges. The simple models we present provide some insights into provision of services through time and intergenerational equity issues (Fig. 2). Incorporating uncertainty, particularly in relationship to potential thresholds (Fig. 3F), provides important insights about the level of risk for contrasting management options and can help society avoid nasty surprises. Given that many social-ecological systems have complex dynamics, consideration of temporal dimensions, nonlinearities, and uncertainties in ecosystem service trade-offs is critical to management efforts aimed at achieving sustainable ecosystem benefits.

The framework reviewed here can be applied to a variety of spatial scales and social-ecological conditions. We emphasize that the framework can be extended to much broader spatial extents, to a range of contexts, and potentially to other forms of capital beyond natural capital, e.g., manufactured capital, human capital, and social capital, that contribute to human well-being. Although many challenges remain, the process of working through the framework in a particular study system or management scenario provides valuable insights that can help bridge contrasting perspectives. This latter point speaks to our primary goal in presenting this review, which is to communicate across disciplines and perspectives to enhance tools for confronting the essential challenge of sustainability, which is meeting human needs without depleting the Earth's capacity to meet those needs in the future.

\section{Responses to this article can be read online at:}

http://www.ecologyandsociety.org/issues/responses. php/6917

\section{Acknowledgments:}

We thank the National Center for Ecological Analysis and Synthesis and the Institute on Environment at the University of Minnesota for funding, and the many scholars involved in the Distributed Graduate Seminar on Sustainability Science between
2010 and 2013 for insights. We also thank the Long Term Ecological Research Network Office for funding a catalysis meeting on sustainability science. Finally, we thank Emma Goldberg for technical help with the model in Figure 3D, and William C. Clark, Osvaldo Sala, and an anonymous reviewer for comments on a previous version of the manuscript.

\section{LITERATURE CITED}

Alexandratos, N., and J. Bruinsma. 2012. World agriculture towards 2030/2050, the 2012 revision. ESA Working Paper No. 12-03. Food and Agriculture Organization, Rome, Italy.

Anbumozhi, V., J. Radhakrishnanb, and E. Yamajic. 2005. Impact of riparian buffer zones on water quality and associated management considerations. Ecological Engineering 24:517-523. http://dx.doi.org/10.1016/j.ecoleng.2004.01.007

Anderies J. M., M. A. Janssen, and E. Ostrom. 2004. A framework to analyze the robustness of social-ecological systems from an institutional perspective. Ecology and Society 9(1): 18. [online] URL: http://www.ecologyandsociety.org/vol9/iss1/art18/

Arrow, K. J., P. Dasgupta, L. Goulder, G. Daily, P. Ehrlich, G. Heal, S. Levin, K. G. Maler, S. Schneider, D. Starrett, and B. Walker. 2004. Are we consuming too much? Journal of Economic Perspectives 18:147-172. http://dx.doi.org/10.1257/0895330042162377

Arrow, K., P. Dasgupta, L. H. Goulder, K. J. Mumford, and K. Oleson. 2012. Sustainability and the measurement of wealth. Environment and Development Economics 17:317-353. http://dx. doi.org/10.1017/S1355770X12000137

Arrow, K., and A. C. Fisher. 1974. Environmental preservation, uncertainty, and irreversibility. Quarterly Journal of Economics 88:312-319. http://dx.doi.org/10.2307/1883074

Bateman, I. J., A. R. Harwood, G. M. Mace, R. T. Watson, D. J. Abson, B. Andrews, A. Binner, A. Crowe, B. H. Day, S. Dugdale, C. Fezzi, J. Foden, D. Hadley, R. Haines-Young, M. Hulme, A. Kontoleon, A. A. Lovett, P. Munday, U. Pascual, J. Paterson, G. Perino, A. Sen, G. Siriwardena, D. van Soest, and M. Termansen. 2013. Bringing ecosystem services into economic decisionmaking: land use in the United Kingdom. Science 341:45-50. http://dx.doi.org/10.1126/science.1234379

Bator, F. M. 1957. The simple analytics of welfare maximization. American Economic Review 47:22-59.

Bennett, E. M., C. S. Cumming, and G. D. Peterson. 2005. A systems model approach to determining resilience surrogates for case studies. Ecosystems 8:945-957. http://dx.doi.org/10.1007/ $\underline{\mathrm{s} 10021-005-0141-3}$

Carpenter, S. R., C. Folke, A. Norström, O. Olsson, L. Schultz, B. Agarwal, P. Balvanera, B. Campbell, J. C. Castilla, W. Cramer, R. DeFries, P. Eyzaguirre, T. P. Hughes, S. Polasky, Z. Sanusi, R. Scholes, and M. Spierenburg. 2012. Program on ecosystem change and society: an international research strategy for integrated social-ecological systems. Current Opinion in Environmental Sustainability 4:134-138. http://dx.doi.org/10.1016/i.cosust.2012.01.001

Carpenter, S. R., D. Ludwig, and W. A. Brock. 1999. Management of eutrophication for lakes subject to potentially irreversible change. Ecological Applications 9:751-771. http://dx.doi. org/10.1890/1051-0761(1999)009[0751:MOEFLS]2.0.CO;2 
Carpenter, S. R, H. A. Mooney, J. Agard, D. Capistrano, R. S. DeFries, S. Díaz, T. Dietz, A. K. Duraiappah, A. Oteng-Yeboahi, H. M. Pereira, C. Perrings, W. V. Reid, J. Sarukhan, R. J. Scholes, and A. Whyte. 2009. Science for managing ecosystem services: beyond the Millennium Ecosystem Assessment. Proceedings of the National Academy of Sciences 106:1305-1312. http://dx.doi. org/10.1073/pnas.0808772106

Castillo, A., A. Magaña, A. Pujadas, L. Martínez, and C. Godínez. 2005. Understanding the interaction of rural people with ecosystems: a case study in a tropical dry forest of Mexico. Ecosystems 8:630-643. http://dx.doi.org/10.1007/s10021-005-0127-1

Cavender-Bares, J., J. Heffernan, E. King, S. Polasky, P. Balvanera, and W. C. Clark. 2013. Sustainability and biodiversity. Pages 71-84 in S. E. Levin, editor. Encyclopedia of biodiversity. Second edition. Volume 7. Academic Press, Amsterdam, The Netherlands. http://dx.doi.org/10.1016/B978-0-12-384719-5.00390-7

Champ, P. A., K. J. Boyle, and T. C. Brown, editors. 2003. A primer on nonmarket valuation. Springer, New York, New York, USA. http://dx.doi.org/10.1007/978-94-007-0826-6

Chan, M. A. K., A. D. Guerry, P. Balvanera, S. Klain, T. Satterfield, X. Basurto, A. Bostrom, R. Chuenpagdee, R. Gould, B. S. Halpern, N. Hannahs, J. Levine, B. Norton, M. Ruckelshaus, R. Russell, J. Tam, and U. Woodside. 2012. Where are cultural and social in ecosystem services? A framework for constructive engagement. BioScience 62:744-756. http://dx.doi.org/10.1525/ bio.2012.62.8.7

Chazdon, R. L. 2008. Beyond deforestation: restoring forests and ecosystem services on degraded lands. Science 320:1458-1460. http://dx.doi.org/10.1126/science.1155365

Clark, C. W. 1976. Mathematical bioeconomics: the optimal management of renewable resources. Wiley, Hoboken, New Jersey, USA.

Dasgupta, P., and G. Heal. 1974. The optimal depletion of exhaustible resources. Review of Economic Studies 41:3-28. http:// dx.doi.org/10.2307/2296369

Dasgupta, P., and K.-G. Mäler. 2000. Net national product, wealth and social well-being. Environment and Development Economics 5:69-93. http://dx.doi.org/10.1017/S1355770X00000061

de Groot, R. S., R. Alkemade, L. Braat, L. Hein, and L. Willemen. 2010. Challenges in integrating the concept of ecosystem services and values in landscape planning, management and decision making. Ecological Complexity 7:260-272. http://dx.doi. org/10.1016/j.ecocom.2009.10.006

Díaz, S., F. Quétier, D. M. Cáceres, S. F. Trainor, N. PérezHarguindeguy, M. S. Bret-Harte, B. Finegan, M. Peña-Claros, and L. Poorter. 2011. Linking functional diversity and social actor strategies in a framework for interdisciplinary analysis of nature's benefits to society. Proceedings of the National Academy of Sciences 108:895-902. http://dx.doi.org/10.1073/pnas.1017993108

Ewing, P. M., and B. C. Runck. 2015. Optimizing nitrogen rates in the midwestern United States for maximum ecosystem value. Ecology and Society 20(1): 18. http://dx.doi.org/10.5751/ ES-06767-200118
Foley, J. A., R. DeFries, G. P. Asner, C. Barford, G. Bonan, S. R. Carpenter, F. S. Chapin, M. T. Coe, G. C. Daily, H. K. Gibbs, J. H. Helkowski, T. Holloway, E. A. Howard, C. J. Kucharik, C. Monfreda, J. A. Patz, I. C. Prentice, N. Ramunkutty, and P. K. Snyder. 2005. Global consequences of land use change. Science 309:570-574. http://dx.doi.org/10.1126/science.1111772

Foley, J. A., N. Ramankutty, K. A. Brauman, E. S. Cassidy, J. S. Gerber, M. Johnston, N. D. Mueller, C. O'Connell, D. K. Ray, P. C. West, C. Balzer, E. M. Bennett, S. R. Carpenter, J. Hill, C. Monfreda, S. Polasky, J. Rockström, J. Sheehan, S. Siebert, D. Tilman, and D. P. M. Zaks. 2011. Solutions for a cultivated planet. Nature 478:337-342. http://dx.doi.org/10.1038/nature10452

Freeman, A.M. 2003. The measurement of environmental and resource values: theory and methods. Resources for the Future, Washington, D.C., USA.

Gilliam, J. W. 1994. Riparian wetlands and water quality. Journal of Environmental Quality 23:896-900. http://dx.doi.org/10.2134/ jeq1994.00472425002300050007x

Goldstein, J. H., G. Caldarone, T. K. Duarte, D. Ennaanay, N. Hannahs, G. Mendoza, S. Polasky, S. Wolny, and G. C. Daily. 2012. Integrating ecosystem-service tradeoffs into land-use decisions. Proceedings of the National Academy of Sciences 109:7565-7570. http://dx.doi.org/10.1073/pnas. 1201040109

Grossman, J. J. 2015. Ecosystem Service Trade-offs and Land Use among Smallholder Farmers in Eastern Paraguay. Ecology and Society 20(1):19. http://dx.doi.org/10.5751/ES-06953-200119

Hamilton, K., and M. Clemens. 1999. Genuine saving rates in developing countries. World Bank Economic Review 13:333-356. http://dx.doi.org/10.1093/wber/13.2.333

Heal, G. M. 2000. Valuing the future: economic theory and sustainability. Columbia University Press, New York, New York, USA.

Hein, L., K. van Koppen, R. S. de Groot, and E. C. van Ierland. 2006. Spatial scales, stakeholders and the valuation of ecosystem services. Ecological Economics 57:209-228. http://dx.doi. org/10.1016/j.ecolecon.2005.04.005

Hughes, T. P., A. H. Baird, D. R. Bellwood, M. Card, S. R. Connolly, C. Folke, R. Grosberg, O. Hoegh-Guldberg, J. B. C. Jackson, J. Kleypas, J. M. Lough, P. Marshall, M. Nyström, S. R. Palumbi, J. M. Pandolfi, B. Rosen, and J. Roughgarden. 2003. Climate change, human impacts, and the resilience of coral reefs. Science 301:929-933. http://dx.doi.org/10.1126/science.1085046

Iverson, T., and C. Perrings. 2012. Precaution and proportionality in the management of global environmental change. Global Environmental Change 22:161-177. http://dx.doi.org/10.1016/j. gloenvcha.2011.09.009

Janssen, M. A., J. M. Anderies, and B. H. Walker. 2004. Robust strategies for managing rangelands with multiple stable attractors. Journal of Environmental Economics and Management 47:140-162. http://dx.doi.org/10.1016/S0095-0696(03)00069-X

Kareiva, P. H. Tallis, T. H. Ricketts, G. C. Daily, and S. Polasky. 2011. Natural capital: theory and practice of mapping ecosystem services. Oxford University Press, Oxford, UK. http://dx.doi. org/10.1093/acprof:oso/9780199588992.001.0001 
Keeler, B. L., S. Polasky, K. A. Brauman, K. A. Johnson, J. C. Finlay, A. O'Neill, K. Kovacs, and B. Dalzell. 2012. Linking water quality and well-being for improved assessment and valuation of ecosystem services. Proceedings of the National Academy of Sciences 109:18619-18624. http://dx.doi.org/10.1073/pnas.1215991109

Keller, K., B. M. Bolker, and D. F. Bradford. 2004. Uncertain climate thresholds and economic optimal growth. Journal of Environmental Economics and Management 48(1):723-741. http:// dx.doi.org/10.1016/j.jeem.2003.10.003

Keeney, R. L., and H. Raiffa. 1993. Decisions with multiple objectives: preferences and value trade-offs. Cambridge University Press, Cambridge, UK. http://dx.doi.org/10.1017/CBO9781139174084

Kline, J. D., and M. J. Mazzotta. 2012. Evaluating tradeoffs among ecosystem services in the management of public lands. General Technical Report PNW-GTR. U.S. Forest Service, Pacific Northwest Research Station, Corvallis, Oregon, USA.

Krutilla, J. 1967. Conservation reconsidered. American Economic Review 57(4):777-786.

Laterra, P., M. E. Orúe, and G. C. Booman. 2012. Spatial complexity and ecosystem services in rural landscapes. Agriculture, Ecosystems \& Environment 154:56-67. http://dx.doi. org/10.1016/j.agee.2011.05.013

Lawler J. J., D. J. Lewis, E. Nelson, A. J. Plantinga, S. Polasky, J. C. Withey, D. P. Helmers, S. Martinuzzi, D. Pennington, and V. C. Radeloff. 2014. Projected land-use change impacts on ecosystem services in the U.S. Proceedings of the National Academy of Sciences 111:7492-7497. http://dx.doi.org/10.1073/ pnas. 1405557111

Lemoine, D. M., and C. P. Traeger. 2014. Watch your step: optimal policy in a tipping climate. American Economic Journal: Economic Policy 6:137-166. http://dx.doi.org/10.1257/pol.6.1.137

Lempert, R. J., D. G. Groves, S. W. Popper, and S. C. Bankes. 2006. A general, analytic method for generating robust strategies and narrative scenarios. Management Science 52:514-528. http:// dx.doi.org/10.1287/mnsc. 1050.0472

Lowrance, R., L. S. Altier, J. D. Newbold, R. R. Schnabel, P. M. Groffman, J. M. Denver, D. L. Correll, J. W. Gilliam, J. L. Robinson, R. B. Brinsfield, K. W. Staver, W. Lucas, and A. H. Todd. 1997. Water quality functions of riparian forest buffers in Chesapeake Bay watersheds. Environmental Management 21:687-712. http://dx.doi.org/10.1007/s002679900060

Ma, B. L., J. Ying, L. M. Dwyer, E. G. Gregorich, and M. J. Morrison. 2003. Crop rotation and soil $\mathrm{N}$ amendment effects on maize production in eastern Canada. Canadian Journal of Soil Science 83:483-495. http://dx.doi.org/10.4141/S02-071

MacArthur, R. H., and E. O. Wilson. 1967. Theory of island biogeography. Princeton University Press, Princeton, New Jersey, USA.

Martín-López, B., I. Iniesta-Arandia, M. García-Llorente, I. Palomo, I. Casado-Arzuaga, D. G. Del Amo, E. GómezBaggethun, E. Oteros-Rozas, I. Palacios-Agundez, B. Willaarts, J. A. González, F. Santos-Martín, M. Onaindia, C. LópezSantiago, and C. Montes. 2012. Uncovering ecosystem service bundles through social preferences. PLOS ONE 7:e38970. http:// dx.doi.org/10.1371/journal.pone.0038970
Mastrangelo, M. E., and P. Laterra. 2015. From biophysical to social-ecological trade-offs: integrating biodiversity conservation and agricultural production in the Argentine Dry Chaco. Ecology and Society 20(1):20. http://dx.doi.org/10.5751/ES-0718-200120

May, R. M. 1977. Thresholds and breakpoints in ecosystems with a multiplicity of stable states. Nature 269:471-477. http://dx.doi. org/10.1038/269471a0

Millennium Ecosystem Assessment. 2005. Ecosystems and human well-being: synthesis. Island Press, Washington, D.C., USA.

National Research Council. 2005. Valuing ecosystem services: towards better environmental decision-making. National Academies Press, Washington, D.C., USA.

Nelson, E., G. Mendoza, J. Regetz, S. Polasky, H. Tallis, D. R. Cameron, K. M. A. Chan, G. C. Daily, J. Goldstein, P. M. Kareiva, E. Lonsdorf, R. Naidoo, T. H. Ricketts, and R. Shaw. 2009. Modeling multiple ecosystem services, biodiversity conservation, commodity production, and tradeoffs at landscape scales. Frontiers in Ecology and the Environment 7:4-11. http://dx.doi. org/10.1890/080023

Nelson, E., S. Polasky, D. J. Lewis, A. J. Plantinga, E. Lonsdorf, D. White, D. Bael, and J. J. Lawler. 2008. Efficiency of incentives to jointly increase carbon sequestration and species conservation on a landscape. Proceedings of the National Academy of Sciences 105:9471-9476. http://dx.doi.org/10.1073/pnas.0706178105

Niamir-Fuller, M. 1998. The resilience of pastoral herding in Sahelian Africa. Pages 250-284 in F. Berkes and C. Folke, editors. Linking social and ecological systems: management practices and social mechanisms for building resilience. Cambridge University Press, Cambridge, UK.

Nordhaus, W. 2007. Critical assumptions in the Stern review on climate change. Science 317:201-202. http://dx.doi.org/10.1126/ science. 1137316

Ostrom, E. 2009. A general framework for analyzing sustainability of social-ecological systems. Science 325:419-422. http://dx.doi.org/10.1126/science.1172133

Parker, D. C., S. M. Manson, M. A. Janssen, M. J. Hoffmann, and P. Deadman. 2003. Multi-agent systems for the simulation of land-use and land-cover change: a review. Annals of the Association of American Geographers 93:314-337. http://dx.doi. org/10.1111/1467-8306.9302004

Perrings, C., and B. Walker. 1997. Biodiversity, resilience and the control of ecological-economic systems: the case of fire-driven rangelands. Ecological Economics 22:73-83. http://dx.doi. org/10.1016/S0921-8009(97)00565-X

Polasky, S., S. R. Carpenter, C. Folke, and B. Keeler. 2011. Decision-making under great uncertainty: environmental management in an era of global change. Trends in Ecology and Evolution 26:398-404. http://dx.doi.org/10.1016/j.tree.2011.04.007

Polasky, S., E. Nelson, J. Camm, B. Csuti, P. Fackler, E. Lonsdorf, C. Montgomery, D. White, J. Arthuri, B. Garber-Yonts, R. Haight, J. Kagan, A. Starfield, and C. Tobalske. 2008. Where to put things? Spatial land management to sustain biodiversity and economic returns. Biological Conservation 141:1505-1524. http:// dx.doi.org/10.1016/j.biocon.2008.03.022 
Putz, F. E., and C. Romero. 2001. Biologists and timber certification. Conservation Biology 15:313-314. http://dx.doi. org/10.1046/j.1523-1739.2001.015002313.x

Raudsepp-Hearne, C., G. D. Peterson, and E. M. Bennett. 2010. Ecosystem service bundles for analyzing tradeoffs in diverse landscapes. Proceedings of the National Academy of Sciences 107:5242-5247. http://dx.doi.org/10.1073/pnas.0907284107

Roe, D., D. Thomas, J. Smith, M. Walpole, and J. Elliott. 2011. Biodiversity and poverty: ten frequently asked questions - ten policy implications. International Institute for Environment and Development, London, UK.

Scharf, P. C., and J. A. Lory. 2009. Calibrating reflectance measurements to predict optimal sidedress nitrogen rate for corn. Agronomy Journal 101:615-625. http://dx.doi.org/10.2134/ agronj2008.0111

Scheffer, M. 1990. Multiplicity of stable states in freshwater systems. Hydrobiologia 200-201:475-486. http://dx.doi.org/10.1007/ BF02530365

Scheffer, M. 1997. The ecology of shallow lakes. Chapman and Hall, London, UK.

Scheffer, M., W. Brock, and F. Westley. 2000. Socioeconomic mechanisms preventing optimum use of ecosystem services: an interdisciplinary theoretical analysis. Ecosystems 7:260-272.

Scheffer, M., and S. R. Carpenter. 2003. Catastrophic regime shifts in ecosystems: linking theory to observation. Trends in Ecology \& Evolution 18:648-656. http://dx.doi.org/10.1016/j. tree.2003.09.002

Scheffer, M., S. H. Hosper, M.-L. Meijer, B. Moss, and E. Jeppesen. 1993. Alternative equilibria in shallow lakes. Trends in Ecology \& Evolution 8:275-279. http://dx.doi.org/10.1016/0169-5347 (93)90254-M

Sen, A. K. 1967. Isolation, assurance and the social rate of discount. Quarterly Journal of Economics 81:112-124. http://dx. doi.org/10.2307/1879675

Seppelt, R., C. F. Dormann, F. V. Eppink, S. Lautenbach, and S. Schmidt. 2011. A quantitative review of ecosystem service studies: approaches, shortcomings and the road ahead. Journal of Applied Ecology 48:630-636. http://dx.doi.org/10.1111/j.1365-2664.2010.01952. $\underline{x}$

Smith, F. P., R. Gorddard, A. P. N. House, S. McIntyre, and S. M. Prober. 2012. Biodiversity and agriculture: production frontiers as a framework for exploring trade-offs and evaluating policy. Environmental Science \& Policy 23:85-94. http://dx.doi. org/10.1016/j.envsci.2012.07.013

Smukler, S. M., A. T. O'Geen, and L. E. Jackson. 2012. Assessment of best management practices for nutrient cycling: a case study on an organic farm in a Mediterranean-type climate. Journal of Soil and Water Conservation 67:16-31. http://dx.doi. org/10.2489/jswc.67.1.16

Solow, R. M. 1974. The economics of resources or the resources of economics. American Economic Review 64(2):1-14.
Stern, N., and C. Taylor. 2007. Climate change: risk, ethics and the Stern review. Science 317:203-204. http://dx.doi.org/10.1126/ science. 1142920

Stiglitz, J. E. 1974. Growth with exhaustible natural resources: efficient and optimal growth paths. Review of Economic Studies 41:123-137. http://dx.doi.org/10.2307/2296377

Stiglitz, J. E., A. Sen, and J.-P.Fitoussi. 2009. Report by the Commission on the Measurement of Economic Performance and Social Progress. Commission on the Measurement of Economic Performance and Social Progress, Paris, France.

Tilman, D., C. Balzer, J. Hill, and B. L. Befort. 2011. Global food demand and the sustainable intensification of agriculture. Proceedings of the National Academy of Sciences 108:20260-20264. http://dx.doi.org/10.1073/pnas.1116437108

Tilman, D., K. G. Cassman, P. A. Matson, R. Naylor, and S. Polasky. 2002. Agricultural sustainability and intensive production practices. Nature 418:671-677. http://dx.doi. org/10.1038/nature01014

Tran, T. S., M. Giroux, and M. P. Cescas. 1997. Effect of N rate and application methods on $15 \mathrm{~N}$-labelled fertilizer use by corn [title translated from the French]. Canadian Journal of Soil Science 77:9-19. http://dx.doi.org/10.4141/S95-075

UK National Ecosystem Assessment 2011. The UK national ecosystem assessment: synthesis of the key findings. United Nations Environment Programme's World Conservation Monitoring Centre, Cambridge, UK.

Vetter, S. 2005. Rangelands at equilibrium and non-equilibrium: recent developments in the debate. Journal of Arid Environments 62:321-341. http://dx.doi.org/10.1016/j.jaridenv.2004.11.015

White, C., B. S. Halpern, and C. V. Kappel. 2012. Ecosystem service tradeoff analysis reveals the value of marine spatial planning for multiple ocean uses. Proceedings of the National Academy of Sciences 109:4696-4701. http://dx.doi.org/10.1073/ pnas. 1114215109

Zhang, W., T. H. Ricketts, C. Kremen, K. Carney, and S. M. Swinton. 2007. Ecosystem services and dis-services to agriculture. Ecological Economics 64:253-260. http://dx.doi.org/10.1016/j. ecolecon.2007.02.024 
Appendix 1. A sustainability framework for assessing trade-offs in ecosystem services.

\section{Example 1. An efficiency frontier for biodiversity and agricultural productivity}

Here, a trade-off is apparent between the biodiversity or species richness ( $\mathrm{S}$; a supporting ecosystem service or ecological function) that can be sustained from land area in natural habitat $\left(\mathrm{A}_{\mathrm{H}}\right)$ on the one hand, and the agricultural production (P; a provisioning service) that can be derived from land area dedicated to crops $\left(A_{C}\right)$ which is the provisioning service, on the other hand. The conceptual basis for this trade-off is well-grounded in empirical relationships between habitat area and species richness, originally harnessed in the development of the theory of island biogeography (MacArthur and Wilson 1967). The mathematical expression takes into account the total land area $\left(\mathrm{A}_{T}\right)$ that can be partitioned between habitat $\left(\mathrm{A}_{H}\right)$ and $\operatorname{crop}\left(\mathrm{A}_{\mathrm{C}}\right)$ production such that

$$
\mathrm{A}_{\mathrm{T}}=\mathrm{A}_{\mathrm{H}}+\mathrm{A}_{\mathrm{C}}
$$

Both species richness and agricultural production are a function of area such that

$$
S=\alpha A_{H}^{z} \text { and } P=\beta A_{C}
$$

where $\mathrm{z}$ is the slope of the $\log$-log relationship between $S$ and $A_{H}, \alpha$ is a constant ( $y$ intercept) and $\beta$ is the crop yield per unit area. Note that $z, \alpha$ and $\beta$ are context dependent and must be empirically determined. The relationship between species richness (S) and agricultural production (P) can thus be written as:

$$
S=\alpha(1-P / \beta)^{z}
$$

and visualized in Fig. 1A for two contrasting biophysical contexts.

\section{Superimposing human preferences on the efficiency frontier}


Utility represents the benefit or contribution to well-being of ecosystem services. We can define a utility function (U) that describes the willingness of consumers to give up a unit of a provisioning ecosystem service, $x$ (e.g., agricultural productivity) for more of another ecosystem service, y (e.g., biodiversity), such that

$$
\mathrm{U}(\mathrm{x}, \mathrm{y})=\Phi \ln \mathrm{x}+\Psi \mathrm{y}
$$

Where $\Phi$ is the loss of biodiversity attributable to provisioning of agricultural productivity and $\boldsymbol{\Psi}$ is the marginal utility, or the added benefit of an additional unit of biodiversity. Parameters $\Phi$ and $\Psi$ can be assigned to allow the curve to approximate empirically determined preference combinations. Increasing levels of utility for a given stakeholder (Fig. 1B) can be superimposed on the efficiency frontier, as in Figure 1C, to show which of the biophysically possible outcomes provides highest utility for a given stakeholder.

\section{Example 2. Water quality and agricultural productivity}

We assume that crop production ( $\mathrm{P}$; for example, bushels of corn per year) is enhanced by the application of nitrogen fertilizer according to a monod function such that $\mathrm{P}$ depends on the maximum production rate $\left(\mathrm{P}_{\max }\right)$, the quantity of nutrients applied $(\mathrm{N})$, and the half saturation constant of $\mathrm{P}_{\max }\left(\mathrm{h}_{\mathrm{P}}\right)$, such that

$$
\mathrm{P}=\mathrm{P}_{\max }\left(\mathrm{N} / \mathrm{N}+\mathrm{h}_{\mathrm{P}}\right)
$$

The function depends in part on the spatial and temporal precision of fertilizer application, which can influence both $\mathrm{P}_{\max }$ and $\mathrm{h}_{\mathrm{P}}$; enhanced timing of fertilizer addition to coincide with early summer corn growth has been shown in many cases to increase nutrient use efficiency and crop productivity (Tran, Giroux et al. 1997; Ma, Ying et al. 2003; Scharf and Lory 2009). The relationship between agricultural productivity and nutrients applied is shown in Fig. 3A by the black line. 
Appendix 1. A sustainability framework for assessing trade-offs in ecosystem services ES-2014-6917, J. Cavender-Bares, S. Polasky, E. King and P. Balvanera

The red line shows the curve that results with greater precision in fertilizer addition aided by technological advances. Nutrients taken up and stored by the terrestrial ecosystem (Fig. 2B) are represented by a monod function in which $\mathrm{N}_{\max }$ represents the maximum nutrient uptake and $\mathrm{h}_{\mathrm{N}}$ is the half saturation constant.

$$
\mathrm{N}_{\text {storage }}=\mathrm{N}_{\max }\left(\mathrm{N} / \mathrm{N}+\mathrm{h}_{\mathrm{N}}\right) \text {. }
$$

The extent to which applied nutrients $(\mathrm{N})$ are taken up or leaked into neighboring shallow water bodies (Fig. 3C) depends on the efficacy of plant uptake, soil adsorption and land-use management, which are reflected in the $N_{\max }$ and $h_{N}$ parameters. Shifts in human land-management practices, such as inclusion of riparian buffer strips and cover crops are known to increase ecosystem nutrient storage and reduce nutrient runoff (Gilliam 1994; Lowrance, Altier et al. 1997; Anbumozhia, Radhakrishnanb et al. 2005; Smukler, O'Geen et al. 2012) as we simulate in Fig. 2B. Two different management practices are shown, one in which ecosystem nutrient storage is low (black line) and one in which it is high (blue line).

Nutrient runoff in the water $\left(\mathrm{N}_{\text {water }}\right)$ is a function of the maximum nutrient uptake of the terrestrial system ( $\left.\mathrm{N}_{\text {storage }}\right)$, as above, the half saturation constant $\left(\mathrm{h}_{\mathrm{N}}\right)$ of $\mathrm{N}_{\max }$ and the quantity of nutrients applied to crops $(\mathrm{N})$, such that

$$
\mathrm{N}_{\text {water }}=\alpha\left(\mathrm{N}-\left[\mathrm{N}_{\max }\left(\mathrm{N} / \mathrm{N}+\mathrm{h}_{\mathrm{N}}\right)\right] .\right.
$$

We use this function in Fig. 2C to simulate nutrient runoff in relation to applied nutrients for the two cases in which terrestrial ecosystem nutrient storage is high (blue line) and low (black line).

Water quality in shallow lakes depends on the growth of algae that cause turbidity (Keeler, Polasky et al. 2012). Water quality (W), the regulating service of interest, is negatively proportional to algal population size (A). The increased amount of nutrients into waterways causes algal growth, turbidity increase and water quality decline. Water quality was modeled as a function of algal growth, 
Appendix 1. A sustainability framework for assessing trade-offs in ecosystem services ES-2014-6917, J. Cavender-Bares, S. Polasky, E. King and P. Balvanera

nutrients in the water, and growth of aquatic plants by Scheffer (1990) and Scheffer et al (1993). The model is based on the observations that: 1) algal growth, and hence turbidity, increase with nutrient enrichment, but aquatic plants are less affected;2) vegetation growth has a negative effect on turbidity by reducing re-suspension of bottom material and providing refuge for zooplankton grazers; and 3) vegetation area declines with turbidity in a sigmoidal way due to light extinction. The complex relationship between water nutrient concentration and algae populations (Fig. 3D) depends on various simple relationships. Algal growth $(\mathrm{dA} / \mathrm{dt})$ is basically logistic and depends on the intrinsic growth rate of algae ( $\mathrm{r}$ ) and the population size (A). Growth increases with nutrient concentrations $(\mathrm{N})$ and decreases with vegetation (V) in a monod fashion with the half-saturation constants for nutrients $\left(h_{N}\right)$ and for vegetation $\left(h_{\mathrm{v}}\right)$. There is a negative effect of competition on algal growth that increases with algal population size (A) and the strength of the competition coefficient (c).

$$
\frac{d A}{d t}=r A\left(\frac{N}{N+h_{N}}\right)\left(\frac{h_{V}}{V+h_{V}}\right)-c A^{2}
$$

Vegetation abundance is a negative sigmoidal function of algal biomass $\left(A^{\mathrm{p}}\right)$

$$
V=\frac{h_{A}^{p}}{A^{p}+h_{A}^{p}}
$$

where $h_{A} P$ is a half saturation constant and $p$ is a power that shapes the relationship. Water quality can then be related directly to agricultural productivity for three scenarios in Fig. 3E: using precision agriculture where agricultural productivity is high for a given amount of nutrients added (red curve), where terrestrial ecosystem storage of nutrients is high, prevent some of the runoff into waterways (blue line) and where agricultural productivity and ecosystem nutrient storage are comparatively low for a given amount of nutrients added (black line).

Variability in ecosystem nutrient storage and leakage as the result of soil, vegetation and landscape features, human management practices and climatic variability results in high variability in the efficiency frontier for the tradeoff 
Appendix 1. A sustainability framework for assessing trade-offs in ecosystem services ES-2014-6917, J. Cavender-Bares, S. Polasky, E. King and P. Balvanera

between water quality and agricultural productivity (Fig. 3F). It may thus be difficult to manage for optimal outcomes without exceeding sustainability limits with resulting in diminished ecosystem service benefits (low utility).

\section{Example 3. Ecosystem biomass and cattle density}

The mathematical expression of the tradeoff includes a primary producer growth function, based on Lotka-Volterra,

$$
\mathrm{dB} / \mathrm{dt}=\mathrm{rB}(1-\mathrm{B} / \mathrm{K})
$$

where $\mathrm{B}$ is the ecosystem biomass, $\mathrm{r}$ is the intrinsic growth rate and $\mathrm{K}$ is the carrying capacity. Consumption $(\mathrm{dB} / \mathrm{dt})$ is an indicator of the cattle provisioned per unit time. It can be represented by a saturating function that depends on the consumer density (number of cattle), such that

$$
\mathrm{dB} / \mathrm{dt}=\gamma \mathrm{DB}^{2} /\left(\lambda+\mathrm{B}^{2}\right)
$$

where $\mathrm{D}$ is density of consumers (cattle), and $\gamma$ is the efficacy of consumption. Once consumption has reached a threshold $(\lambda)$, resource needs are met and consumption stays constant, even if resources continue to increase. When a saturating consumption function is coupled with logistic growth of the resource, the steadystate solution can (but does not always) yield the tradeoff surface shown in Figure 4A (black line), with two alternative vegetation states possible for a range of cattle density. Once the steady-state solution for the primary resource growth and consumption functions has been found, the tradeoff surface for ecosystem services can be replotted to represent rates or stocks of the provisioning service. For example, if the rate of provisioning (milk production rate) is desired rather than the stock (the cattle density), the trade-off surface will take a different form, but will represent the same underlying dynamics. 
Appendix 1. A sustainability framework for assessing trade-offs in ecosystem services ES-2014-6917, J. Cavender-Bares, S. Polasky, E. King and P. Balvanera

Population growth of cattle is regulated by ecosystem biomass (B), as well as density dependent effects. Cattle population regulation may occur according to various plausible mechanisms. The change in cattle density $(\mathrm{dD} / \mathrm{dt})$ can be described as an exponential growth function $\left(\mathrm{r}_{2} \mathrm{D}\right)$ that is regulated in various possible ways by biomass loss due to consumption, which is a function of cattle density. Two possibilities are shown:

$$
\begin{aligned}
& \frac{d D}{d t}=r_{\mathbf{2}} D-\frac{\lambda \tau \mathrm{D}}{\lambda+B^{2}} \\
& \frac{d D}{d t}=r_{2} D\left(1-\frac{D}{\lambda+B^{2}}\right)
\end{aligned}
$$

The steady state population density of cattle $(\mathrm{dD} / \mathrm{dt}=0)$ is constant with increasing ecosystem biomass in the first case (red line, Fig. 4A) and increases with increasing ecosystem biomass in the second (red line, Figure 4C). The dynamics of the system are thus driven by the interacting tendencies of the biomass growth and the cattle population growth, which may result in highly fluctuating ecosystem functions/services (Fig. 4B), or very low services at equilibrium (Fig. 4D).

\section{References}

Anbumozhia, V., J. Radhakrishnanb, et al. (2005). "Impact of riparian buffer zones on water quality and associated management considerations." Ecological Engineering 24(5): 517-523.

Gilliam, J. W. (1994). "Riparian wetlands and water quality." Journal of Environmental Quality 23(5): 896-900.

Keeler, B. L., S. Polasky, et al. (2012). "Linking water quality and well-being for improved assessment and valuation of ecosystem services." Proceedings of the National Academy of Sciences 109(45): 18619-18624. 
Appendix 1. A sustainability framework for assessing trade-offs in ecosystem services ES-2014-6917, J. Cavender-Bares, S. Polasky, E. King and P. Balvanera

Lowrance, R., L. S. Altier, et al. (1997). "Water quality functions of riparian forest buffers in Chesapeake Bay watersheds." Environmental Management 21(5): 687-712.

Ma, B. L., J. Ying, et al. (2003). "Crop rotation and soil $\mathrm{N}$ amendment effects on maize production in eastern Canada." Can. J. Soil Sci. 83: 483-495.

MacArthur, R. H. and E. O. Wilson (1967). Theory of Island Biogeography. Princeton, NJ, Princeton University Press.

Scharf, P. C. and J. A. Lory (2009). "Calibrating reflectance measurements to predict optimal sidedress nitrogen rate for corn." Agron. J. 101: 615-625.

Scheffer, M. (1990). "Multiplicity of stable states in freshwater systems." Hydrobiologia 200/201: 475-486.

Scheffer, M., S. H. Hosper, et al. (1993). "Alternative equilibria in shallow lakes." Trends in Ecology \& Evolution 8(8): 275-279.

Smukler, S. M., A. T. O'Geen, et al. (2012). "Assessment of best management practices for nutrient cycling: A case study on an organic farm in a Mediterranean-type climate." Journal of Soil and Water Conservation 67(1): 16-31.

Tran, T. S., M. Giroux, et al. (1997). "Effect of N rate and application methods on 15Nlabelled fertilizer use by corn(In French.)." Can. J. Soil Sci. 77: 9-19. 
Appendix 2. R-code used in models and figures

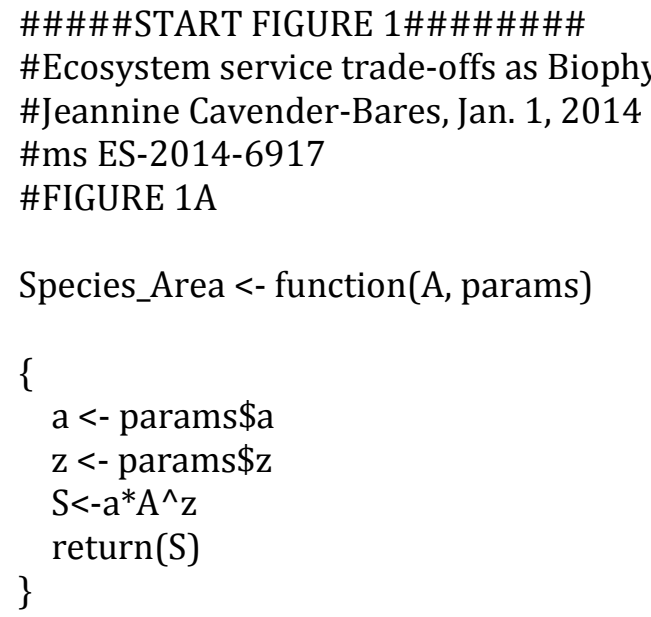


$\mathrm{b}=8$

params $2<-\operatorname{list}(" a "=a, " b "=b, " m "=m, " z "=z)$

\#\#\#\#\#For full area

\# The area values range between 0 and 1 .

$\mathrm{A}<-\operatorname{seq}(0, \mathrm{~m}, \mathrm{by}=0.01)$

\# Get the equilibrium value(s) of $\mathrm{S}$ for each $\mathrm{A}$.

$\mathrm{S}<$ - lapply(A, Species_Area, params)

$\mathrm{x}<-\operatorname{rep}(\mathrm{A}$, unlist(lapply(S, length)))

\# Store the results for species area.

$\mathrm{s}<-$ unlist(S)

$\mathrm{X}<-\operatorname{unlist}(\mathrm{x})$

$\mathrm{SA}<-\operatorname{cbind}(\mathrm{X}, \mathrm{S})$

colnames(SA) <- c("Area", "Species")

SA $<$ - data.frame(SA)

plot(SA $\$$ Area, SA $\$$ Species)

\# Get the value(s) of P for each A.

$\mathrm{P}<-$ lapply(A, Productivity_Area, params)

$\mathrm{t}<-\operatorname{rep}(\mathrm{A}$, unlist(lapply(P, length))

\# Store the results for species area.

$\mathrm{p}<-$ unlist $(\mathrm{P})$

$\mathrm{t}<-$ unlist $(\mathrm{t})$

$\mathrm{PA}<-\operatorname{cbind}(\mathrm{t}, \mathrm{p})$

colnames(PA) <- c("Area", "Productivity")

$\mathrm{PA}<-$ data.frame(PA)

\# Get the value(s) of $C$ for each $A$.

C <- lapply(A, CropArea, params)

$\mathrm{q}<-\operatorname{rep}(\mathrm{A}$, unlist(lapply(C, length))

\# Store the results for species area.

crop $<-$ unlist(C)

$\mathrm{q}<-$ unlist( $\mathrm{q}$ )

AC $<-\operatorname{cbind}(\mathrm{q}$, crop)

colnames(AC) <- c("Area", "CropArea")

$\mathrm{AC}<-$ data.frame $(\mathrm{AC})$

\#merge matrices

L<- merge(SA, PA, by.x="Area", by.y="Area")

$\mathrm{Q}<-$ merge(L, AC, by.X="Area", by.y="Area")

\#\#For different diversity relationship 
\# Get the equilibrium value(s) of $S$ for each $A$.

S <- lapply(A, Species_Area, params2)

$\mathrm{x}<-\operatorname{rep}(\mathrm{A}$, unlist(lapply(S, length)))

\# Store the results for species area.

$\mathrm{s}<-$ unlist(S)

$\mathrm{X}<-\operatorname{unlist}(\mathrm{x})$

$\mathrm{SA} 2<-\operatorname{cbind}(\mathrm{X}, \mathrm{S})$

colnames(SA2) <- c("Area", "Species2")

SA2<- data.frame(SA2)

\#\#\#\#

\#\#For different productivity-area relationship

\# Get the value(s) of $\mathrm{P}$ for each $\mathrm{A}$.

$\mathrm{P}<-$ lapply(A, Productivity_Area, params2)

$\mathrm{t}<-\operatorname{rep}(\mathrm{A}$, unlist(lapply(P, length) $)$ )

\# Store the results for species area.

$\mathrm{p}<-$ unlist $(\mathrm{P})$

$\mathrm{t}<-$ unlist $(\mathrm{t})$

PA2 <- cbind $(\mathrm{t}, \mathrm{p})$

colnames(PA2) <- c("Area", "Productivity2")

PA2<- data.frame(PA2)

\#merge matrices

L2<- merge(Q,SA2, by.X="Area", by.y="Area")

B2<- merge(L2,PA2, by.x="Area", by.y="Area")

\#FIGURE 1A

dev.new(width $=5$, height $=5$ )

$\operatorname{par}(\operatorname{mar}=c(5,5,4,4))$

plot $(Q \$$ Productivity, $Q \$$ Species, $p c h=1, \operatorname{mgp}=c(1,1,0), \operatorname{cex}=0.1$, cex.lab $=1.5$, xaxt='n', yaxt='n',

font $=2$, pin $=c(4,4), x \lim =c(0.5,16), x a x t=' n '$, yaxt='n', ylim $=c(0.5,11), x l a b=$ "Agricultural

Productivity", ylab= "Biodiversity",lwd=0)

axis(lty = "solid",lwd = 2)

lines(Q\$Productivity, Q\$Species, type = "l", lty="solid", lwd =5, xaxt='n', yaxt='n')

box (which = "plot", lty = "solid", col="black", lwd=3)

\#Geographic location with lower species richness per area

par(new=TRUE)

plot(B2 \$Productivity2, B2 \$Species2, pch=1, cex=0.1, cex.lab = 1.5, xaxt='n', yaxt='n', font=2, pin = $c(4,4), x \lim =c(0.5,16), x a x t=' n '$, yaxt='n', ylim $=c(0.5,11), x l a b=" "$, ylab= "')

axis(lty $=$ "solid",lwd $=2$ )

lines(B2\$Productivity2, B2\$Species2, type = "l", lwd =5, col="blue", xaxt='n', yaxt='n')

\#FIGURE 1B 


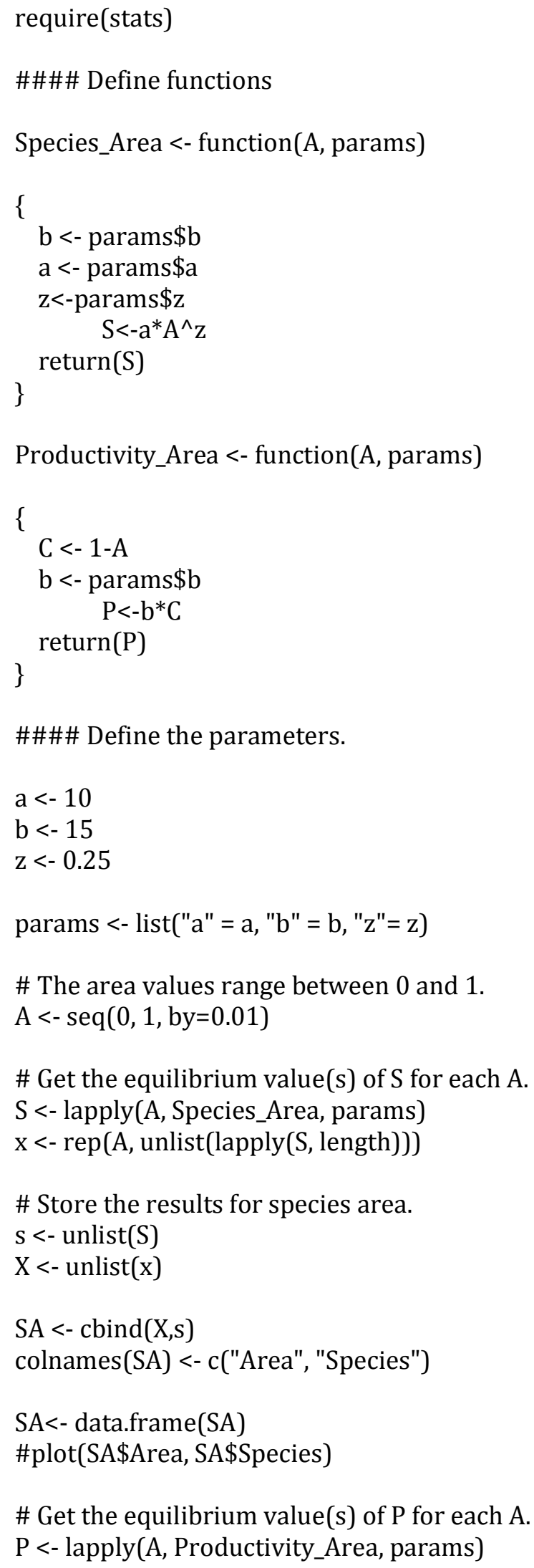




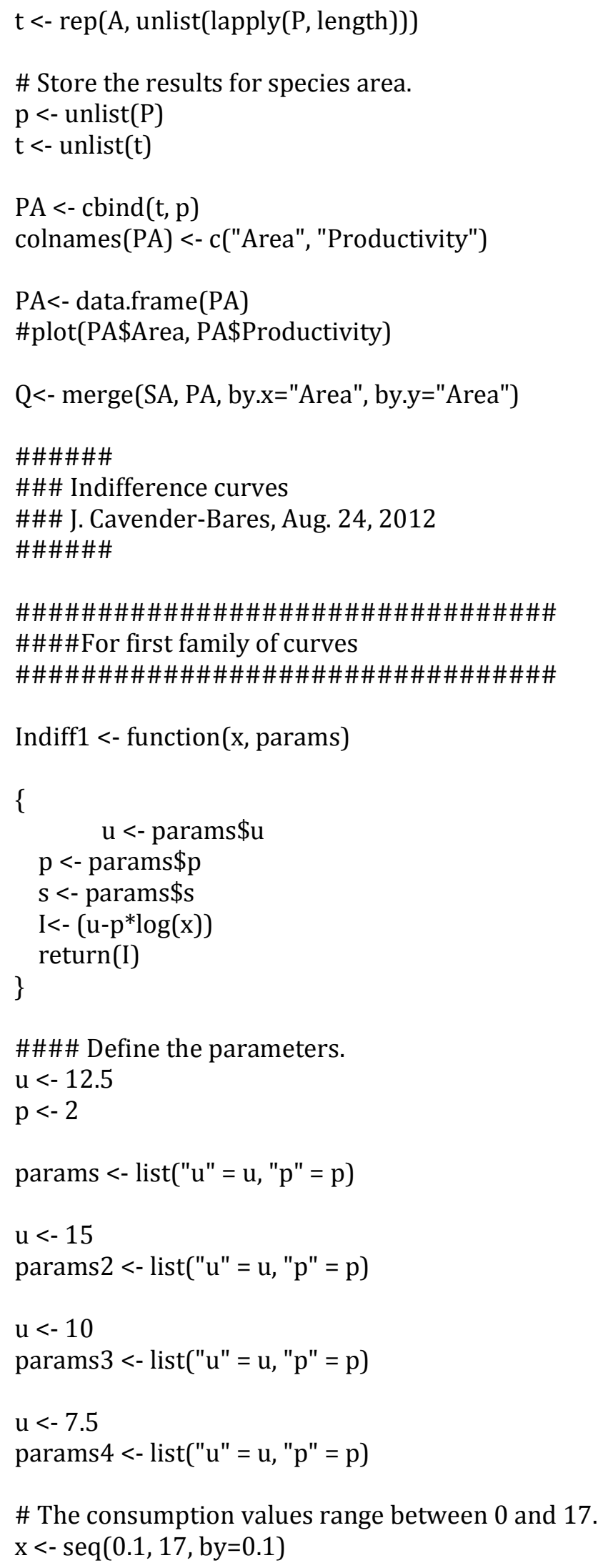


\# Get the value of I for each $\mathrm{x}$.

I <- lapply(x, Indiff1, params)

$\mathrm{z}<-\operatorname{rep}(\mathrm{x}$, unlist(lapply(I, length))

\# Store the results for species area.

$\mathrm{i}<-$ unlist(I)

$\mathrm{Z}<-$ unlist(z)

IC1 <- cbind(Z,i)

colnames(IC1) <- c("Consumption", "Biodiversity1")

IC1<- data.frame(IC1)

\#plot(IC1\$Consumption, IC1\$Biodiversity)

\# For curve 2 Get the value of I3 for each $\mathrm{x}$.

I2 <- lapply(x, Indiff1, params2)

z2 <- rep(x, unlist(lapply(I2, length)))

\# Store the results for species area.

i2 $<-$ unlist(I2)

$\mathrm{Z} 2<-$ unlist(z2)

IC2 <- $\operatorname{cbind}(\mathrm{Z} 2, \mathrm{i} 2)$

colnames(IC2) <- c("Consumption", "Biodiversity2")

IC2 <- data.frame(IC2)

\#plot(IC2\$Consumption, IC2\$Biodiversity)

\# For curve 3 Get the value of I3 for each $\mathrm{x}$.

I3 <- lapply(x, Indiff1, params3)

z3 $<-\operatorname{rep}(\mathrm{x}$, unlist(lapply(I3, length))

\# Store the results for species area.

i3 <- unlist(I3)

$\mathrm{Z} 3<-$ unlist(z3)

IC3 <- cbind $(Z 3, \mathrm{i} 3)$

colnames(IC3) <- c("Consumption", "Biodiversity3")

IC3<- data.frame(IC3)

\#plot(IC3\$Consumption, IC3\$Biodiversity3)

\# For curve 4 Get the value of I4 for each $\mathrm{x}$.

I4 <- lapply(x, Indiff1, params4)

$\mathrm{z} 4<-\operatorname{rep}(\mathrm{x}$, unlist(lapply(I4, length)))

\# Store the results for species area.

i4 <- unlist(I4)

Z4 <- unlist(z4) 


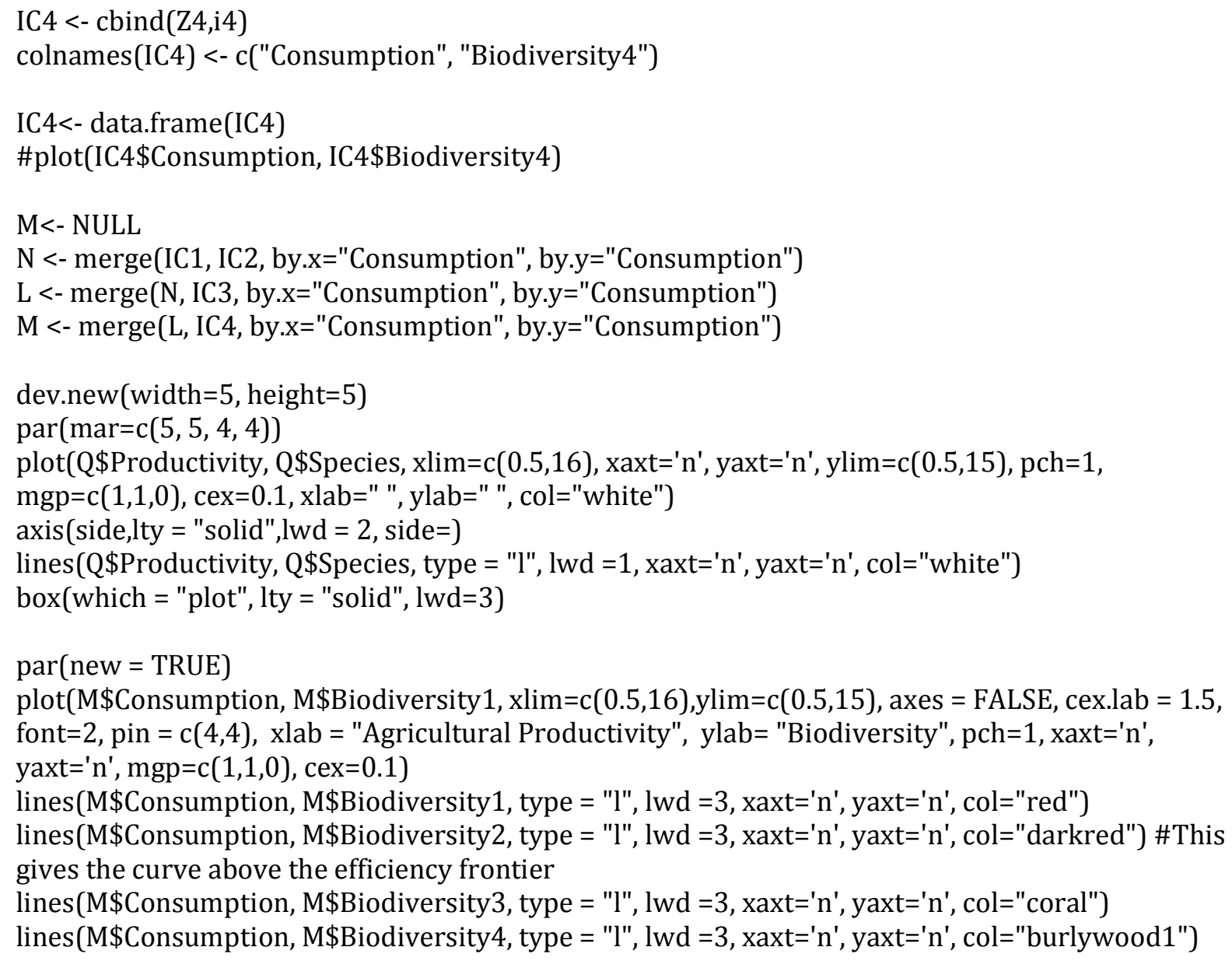




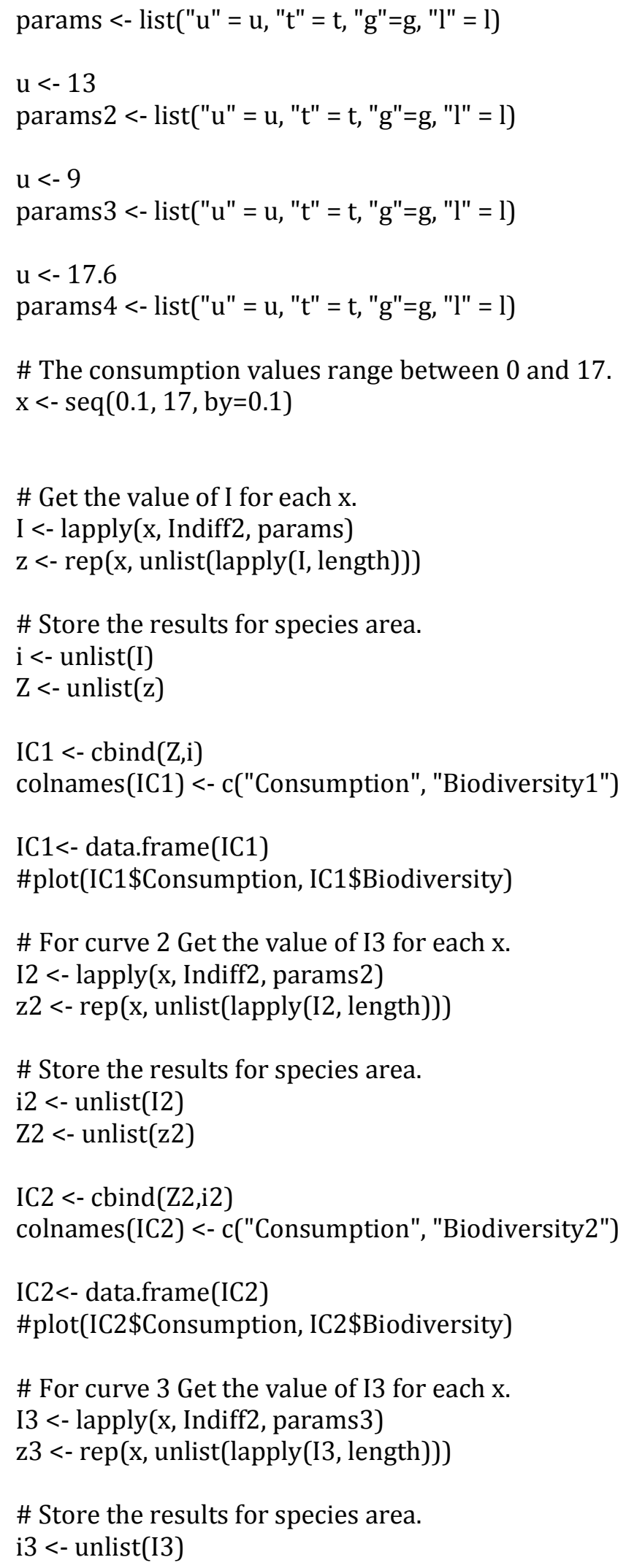




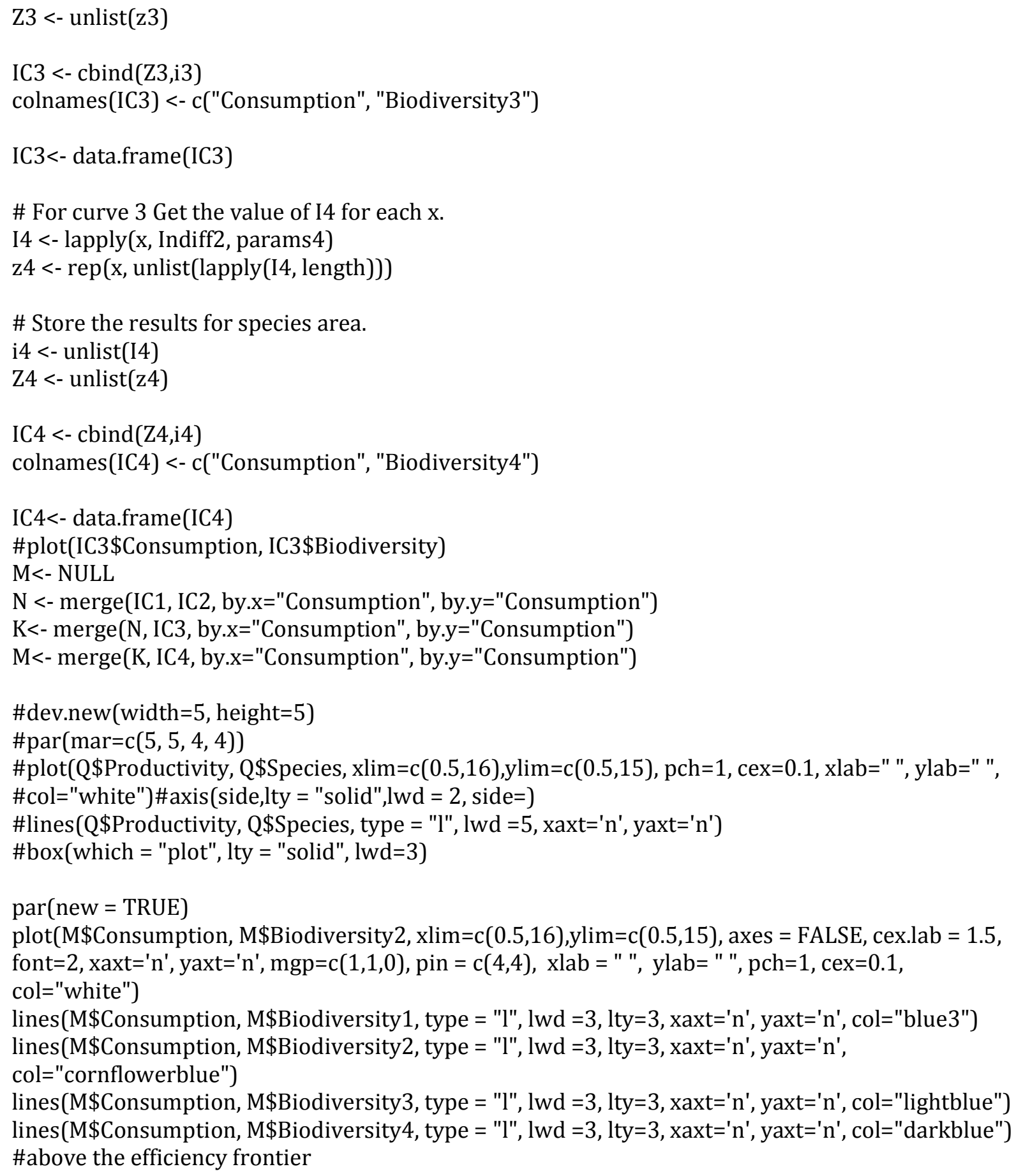




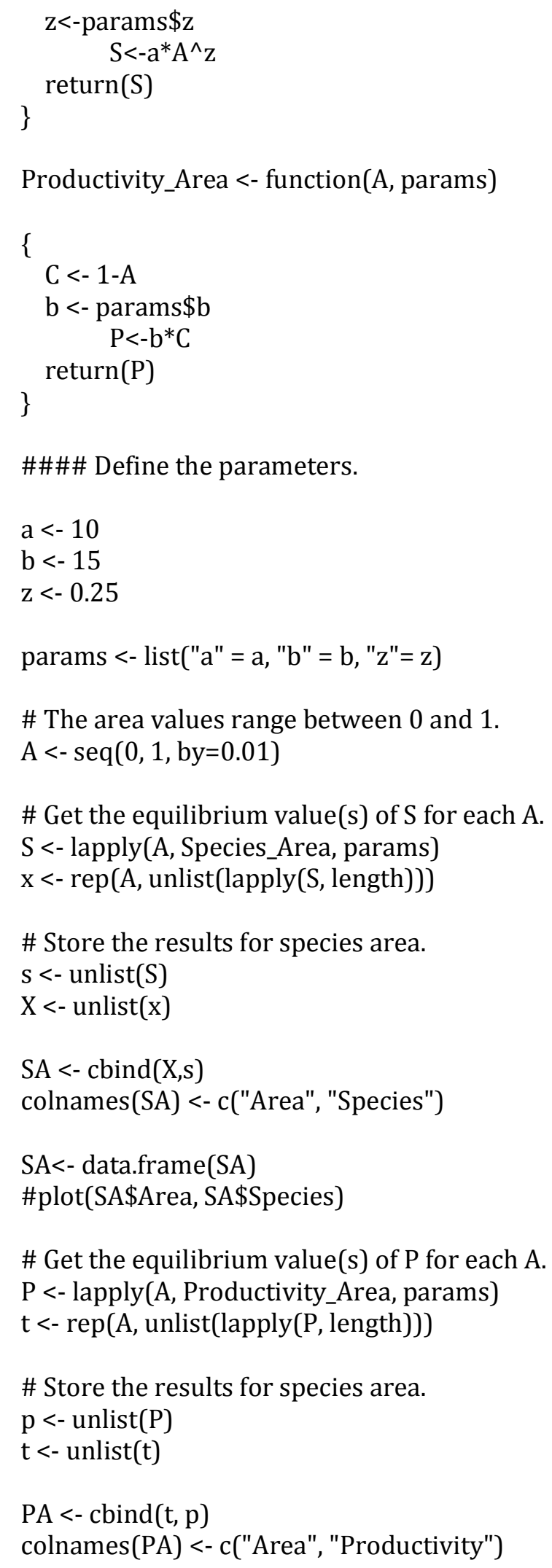


$\mathrm{PA}<-$ data.frame(PA)

\#plot(PA\$Area, PA $\$$ Productivity)

Q<- merge(SA, PA, by.x="Area", by.y="Area")

\#\#\#\#\#\#

\#\#\# Indifference curves

\#\#\# J. Cavender-Bares, Aug. 24, 2012

\#\#\#\#\#\#

\#\#\#\#\#\#\#\#\#\#\#\#\#\#\#\#\#\#\#\#\#\#\#\#\#\#\#\#\#\#\#\#

\#\#\#\#For first family of curves

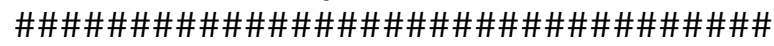

\#\#\#\# Define the parameters.

$\mathrm{u}<-12.5$

$\mathrm{p}<-2$

params <- list("u" = u, "p" = p)

$\mathrm{u}<-15$

params $2<-\operatorname{list}(" \mathrm{u} "=\mathrm{u}, \mathrm{p} "=\mathrm{p})$

$\mathrm{u}<-10$

params3 <- list("u" = u, "p" = p)

$\mathrm{u}<-7.5$

params4 <- list("u" = u, "p" = p)

\# The consumption values range between 0 and 17 .

$\mathrm{x}<-\operatorname{seq}(0.1,17$, by=0.1)

\# Get the value of I for each $\mathrm{x}$.

I <- lapply(x, Indiff1, params)

$\mathrm{z}<-\operatorname{rep}(\mathrm{x}$, unlist(lapply(I, length))

\# Store the results for species area.

$\mathrm{i}<-$ unlist(I)

$\mathrm{Z}<-$ unlist( $\mathrm{z}$ )

IC1 $<-\operatorname{cbind}(\mathrm{Z}, \mathrm{i})$

colnames(IC1) <- c("Consumption", "Biodiversity1")

IC1<- data.frame(IC1)

\#plot(IC1\$Consumption, IC1\$Biodiversity)

\# For curve 2 Get the value of I3 for each $\mathrm{x}$.

I2 <- lapply(x, Indiff1, params2)

z2 <- rep(x, unlist(lapply(I2, length))) 


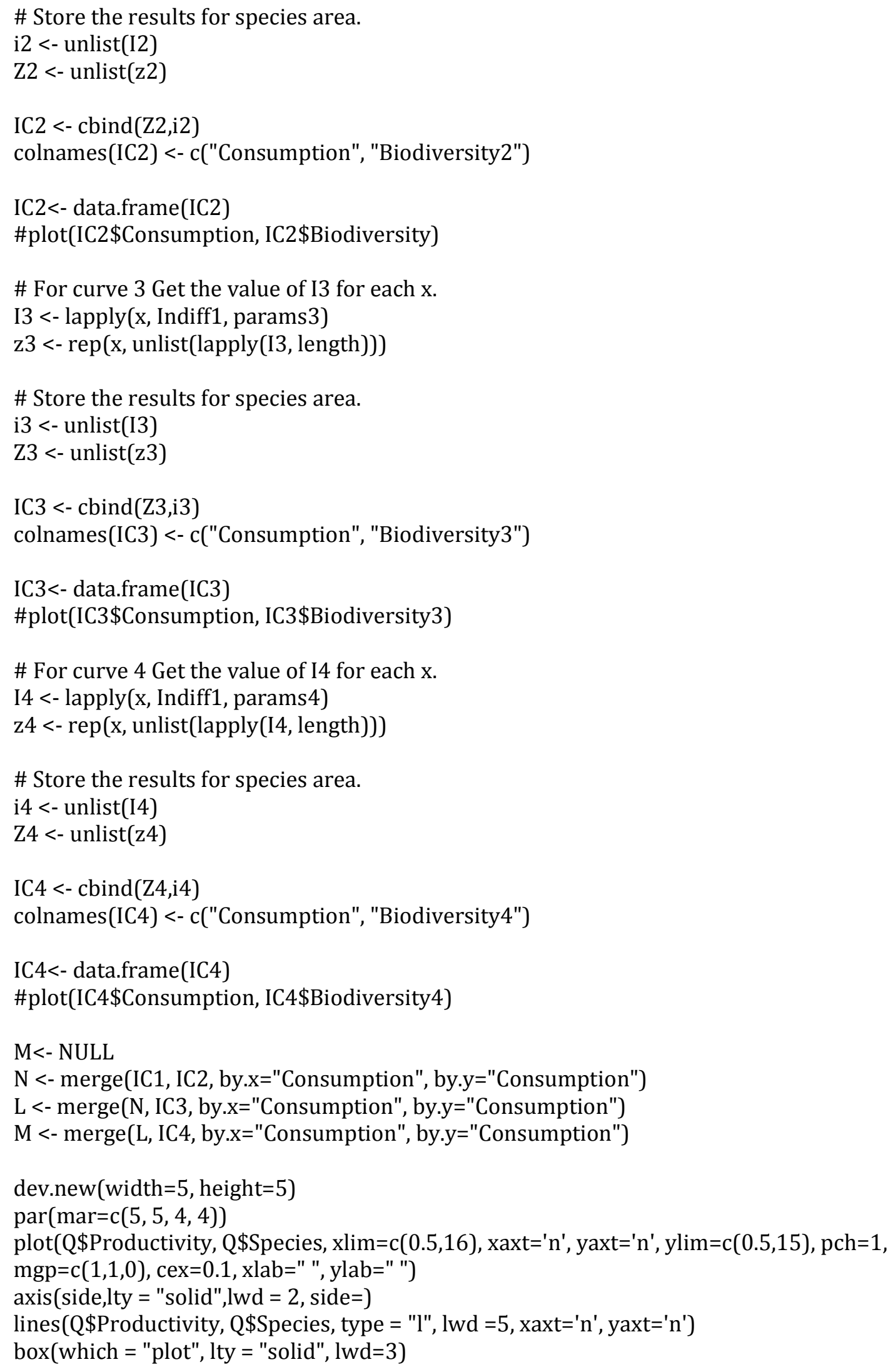


$\operatorname{par}($ new $=$ TRUE $)$

plot(M $\$$ Consumption, M\$Biodiversity1, $x \lim =c(0.5,16)$,ylim=c $(0.5,15)$, axes $=$ FALSE, cex.lab = 1.5, font=2, pin = c(4,4), xlab = "Agricultural Productivity", ylab= "Biodiversity", pch=1, xaxt='n', yaxt='n', mgp=c(1,1,0), cex=0.1)

lines(M\$Consumption, M\$Biodiversity1, type = "l", lwd =3, xaxt='n', yaxt='n', col="red")

lines(M\$Consumption, M\$Biodiversity2, type = "l", lwd =3, xaxt='n', yaxt='n', col="darkred") \#This gives the curve above the efficiency frontier

lines(M\$Consumption, M\$Biodiversity3, type = "l", lwd =3, xaxt='n', yaxt='n', col="coral") lines(M\$Consumption, M\$Biodiversity4, type = "l", lwd =3, xaxt='n', yaxt='n', col="burlywood1")

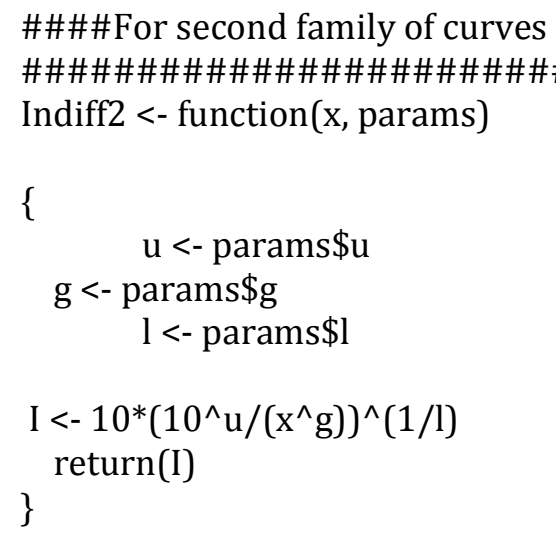




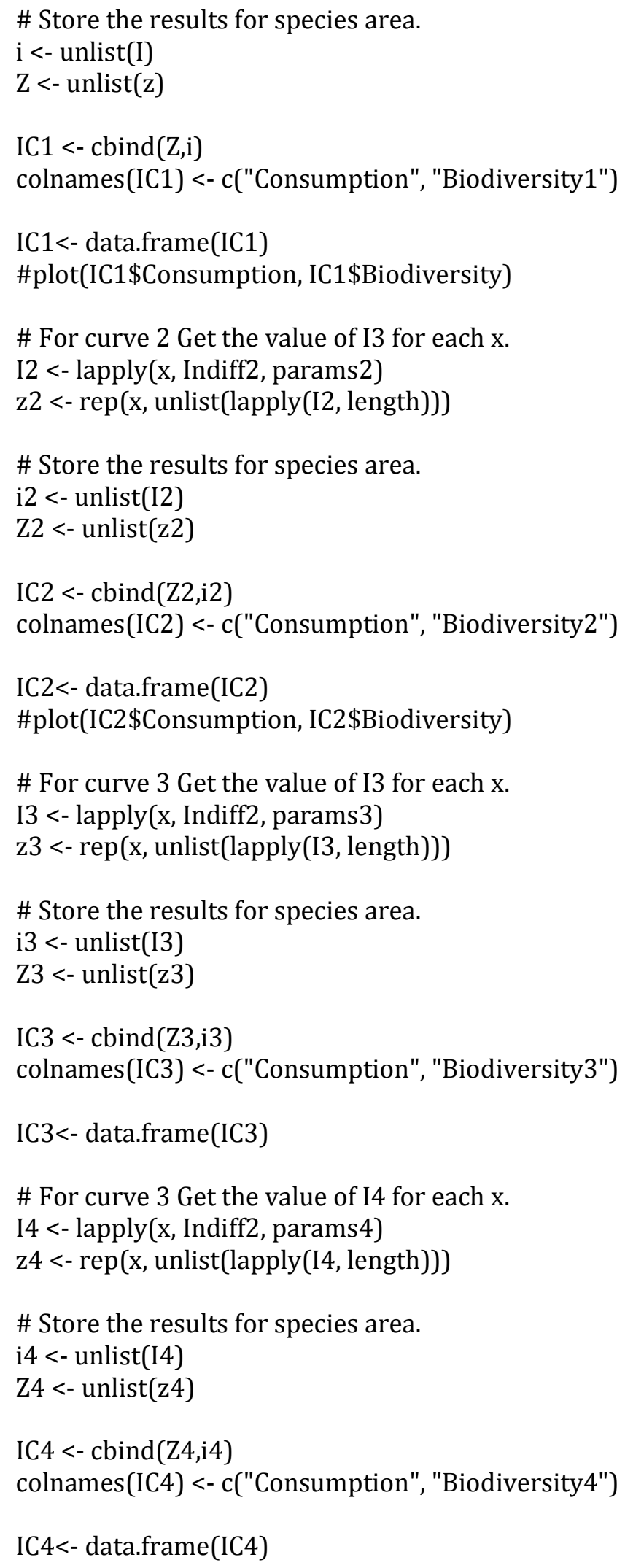




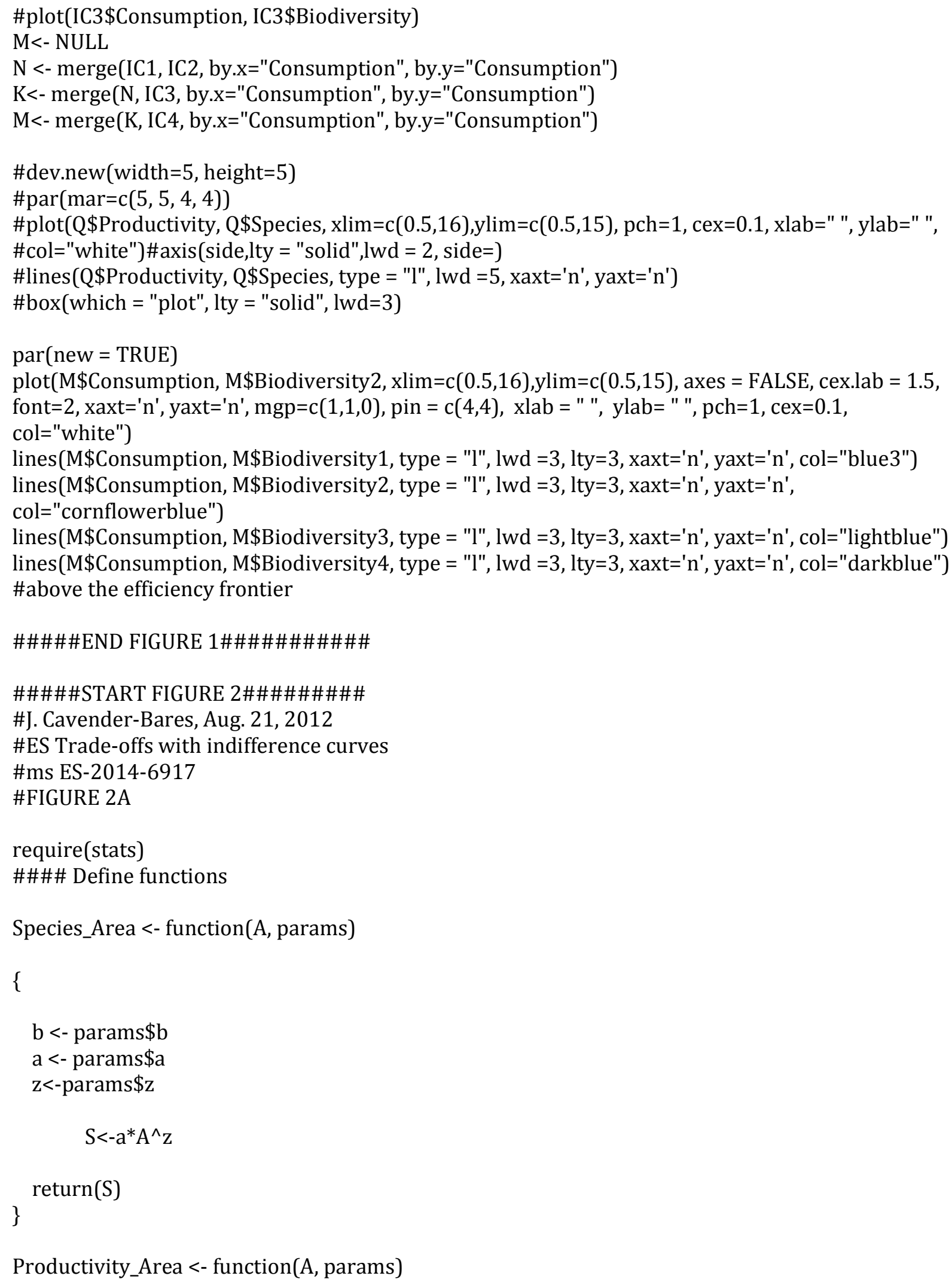




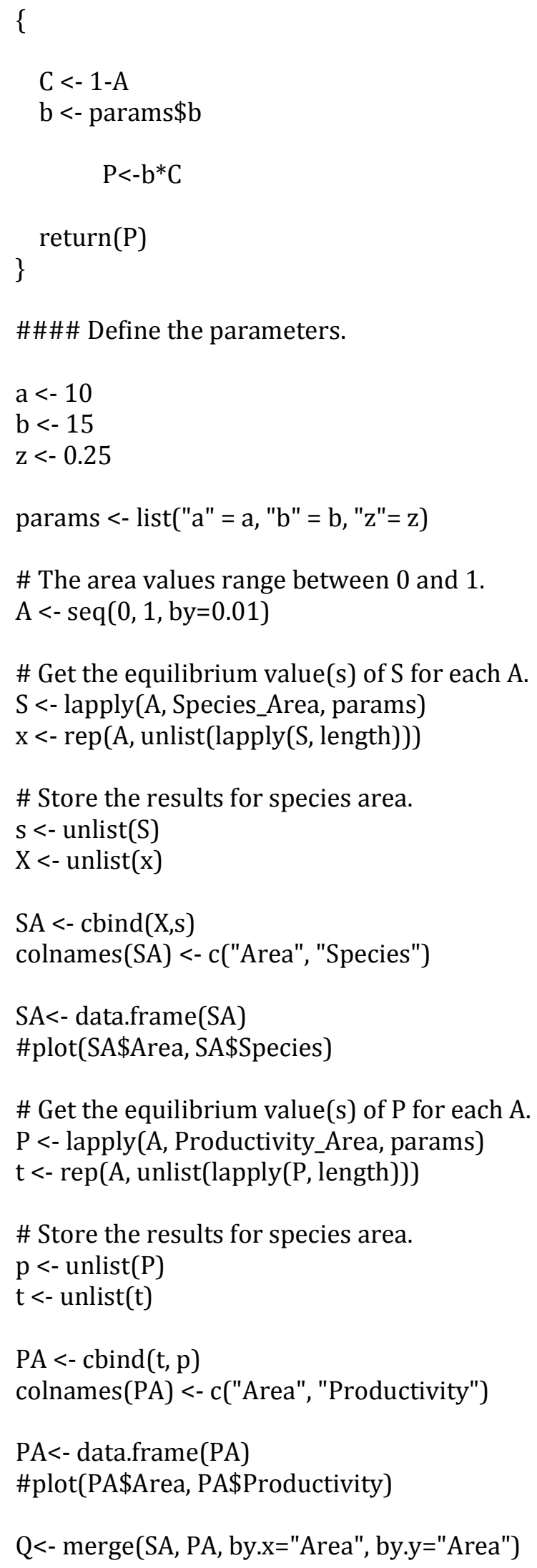




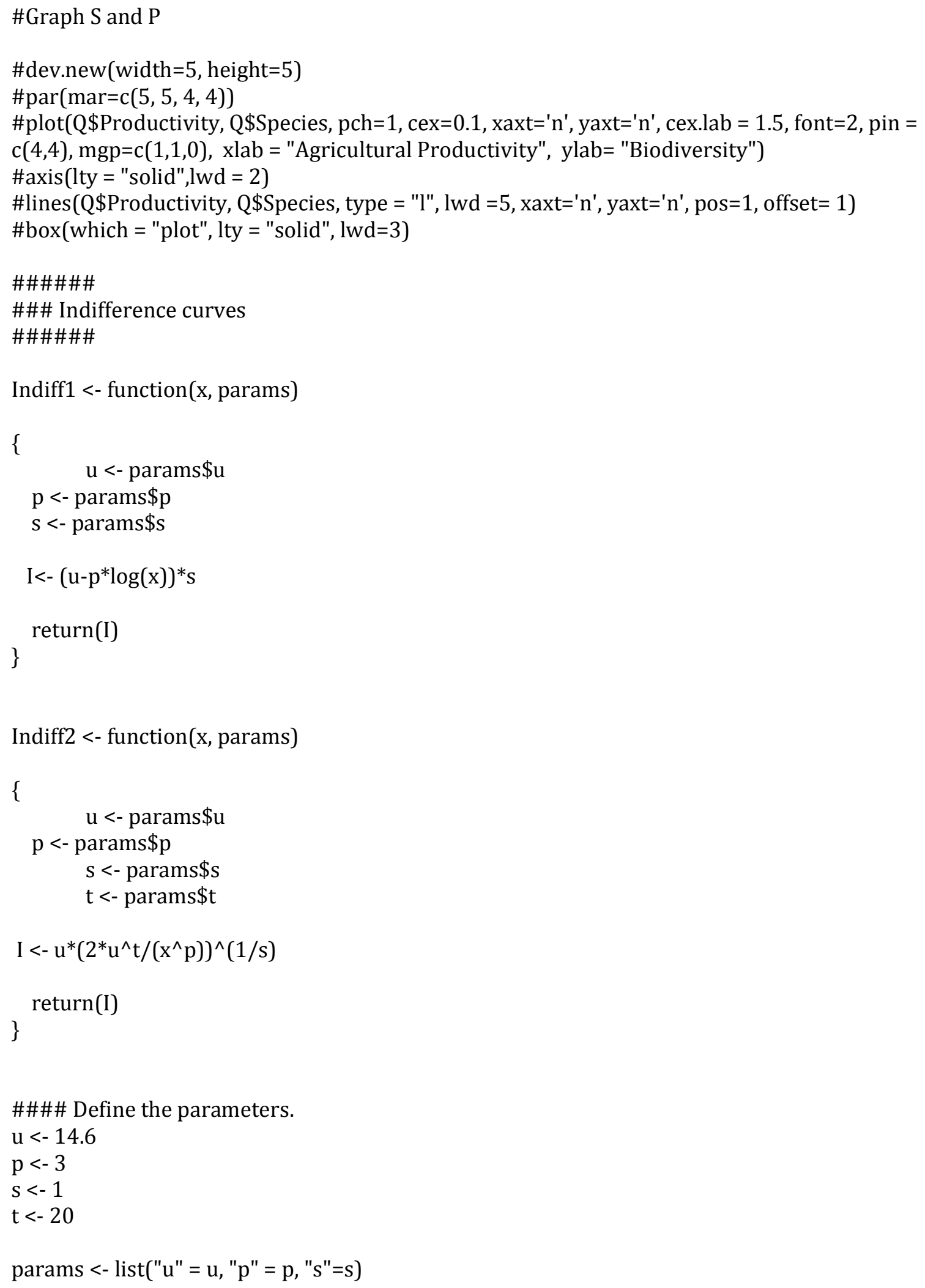









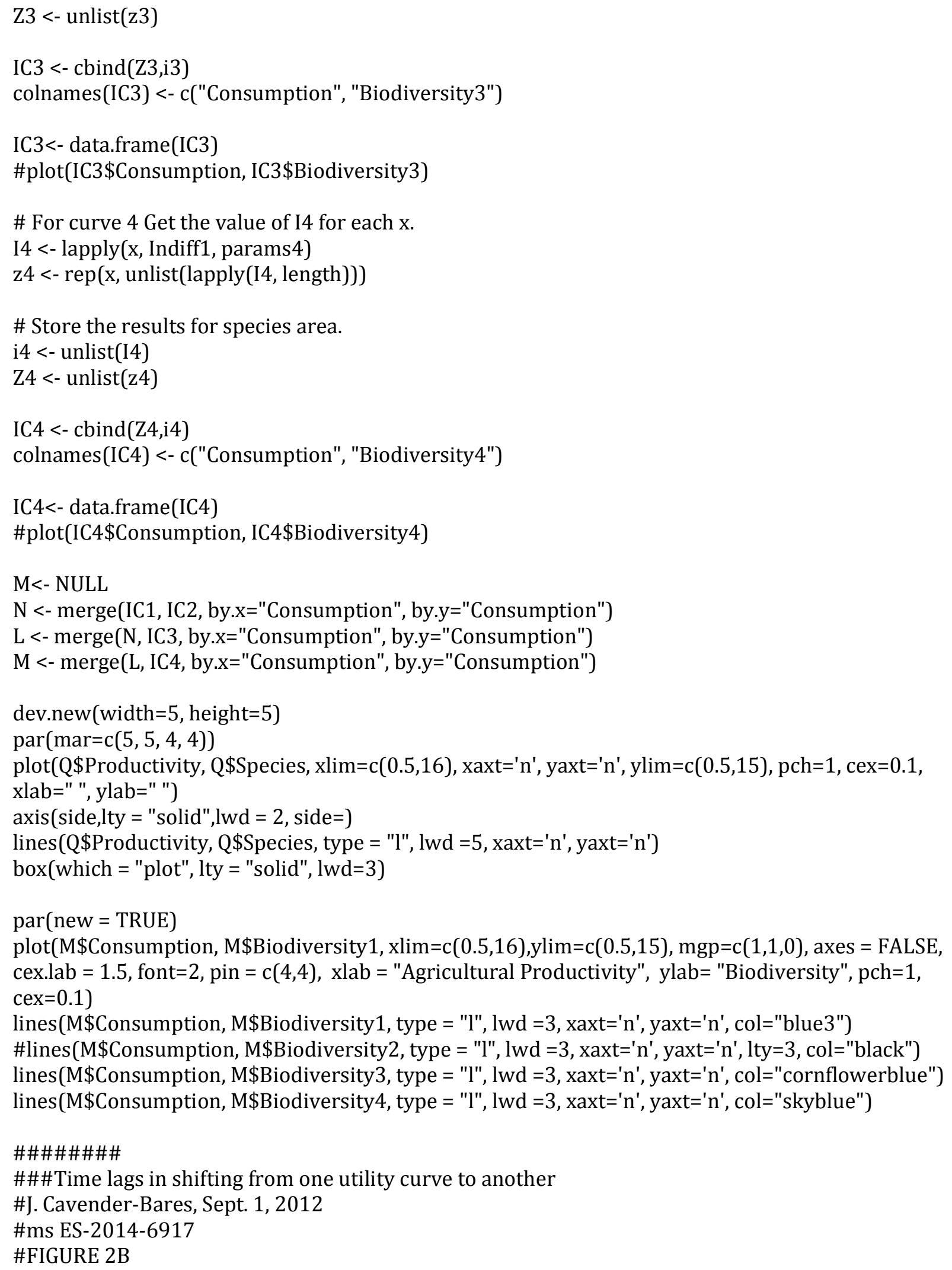




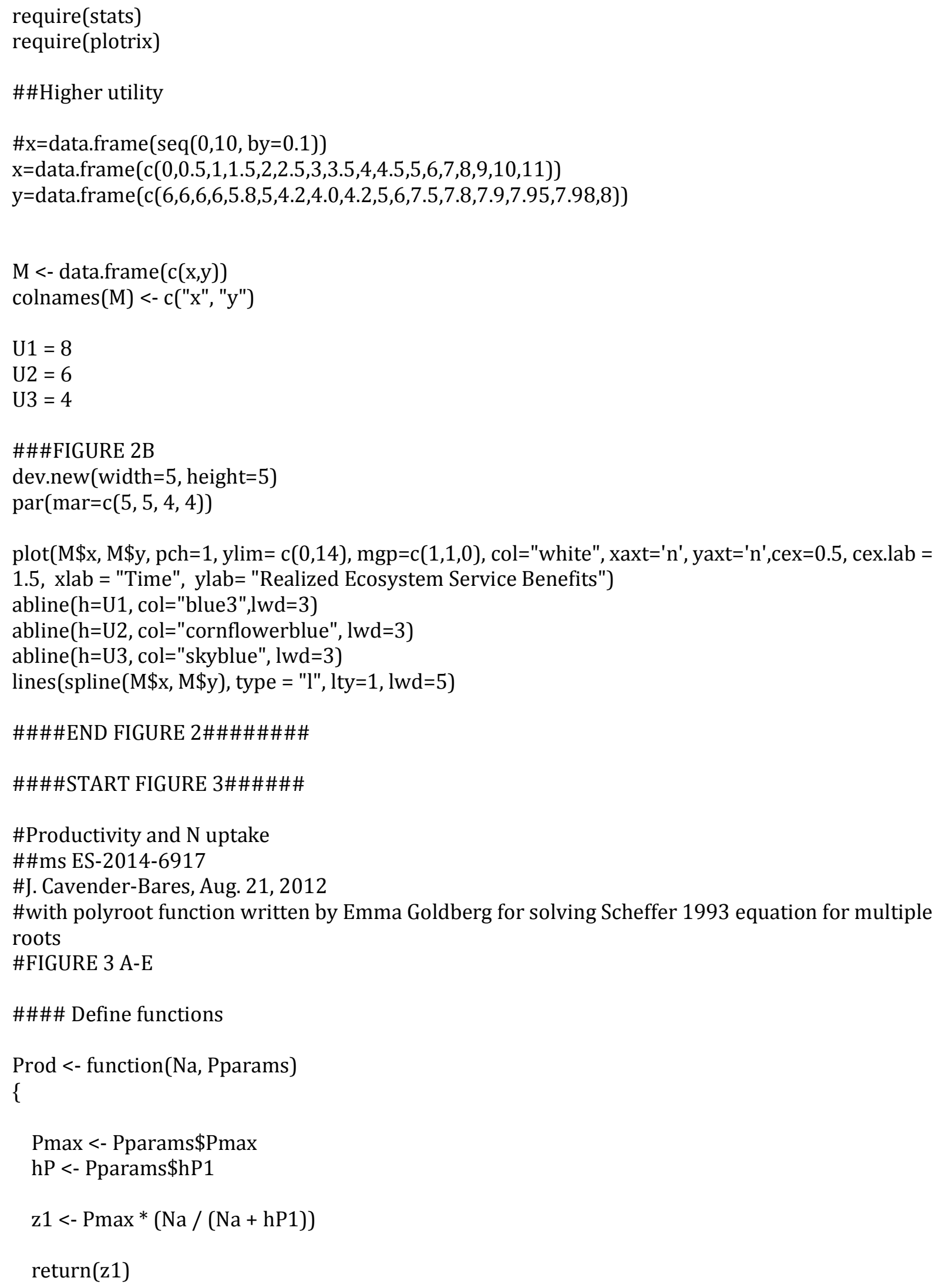


goodProd <- function(Na, Pparams)

\{

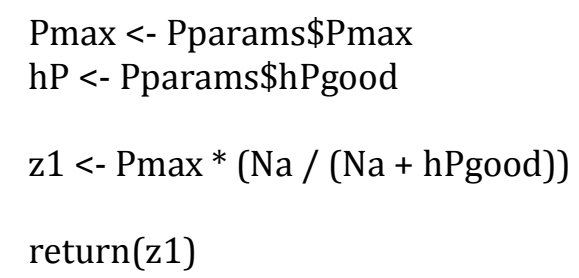

Nuptake<- function(Na, Pparams) 


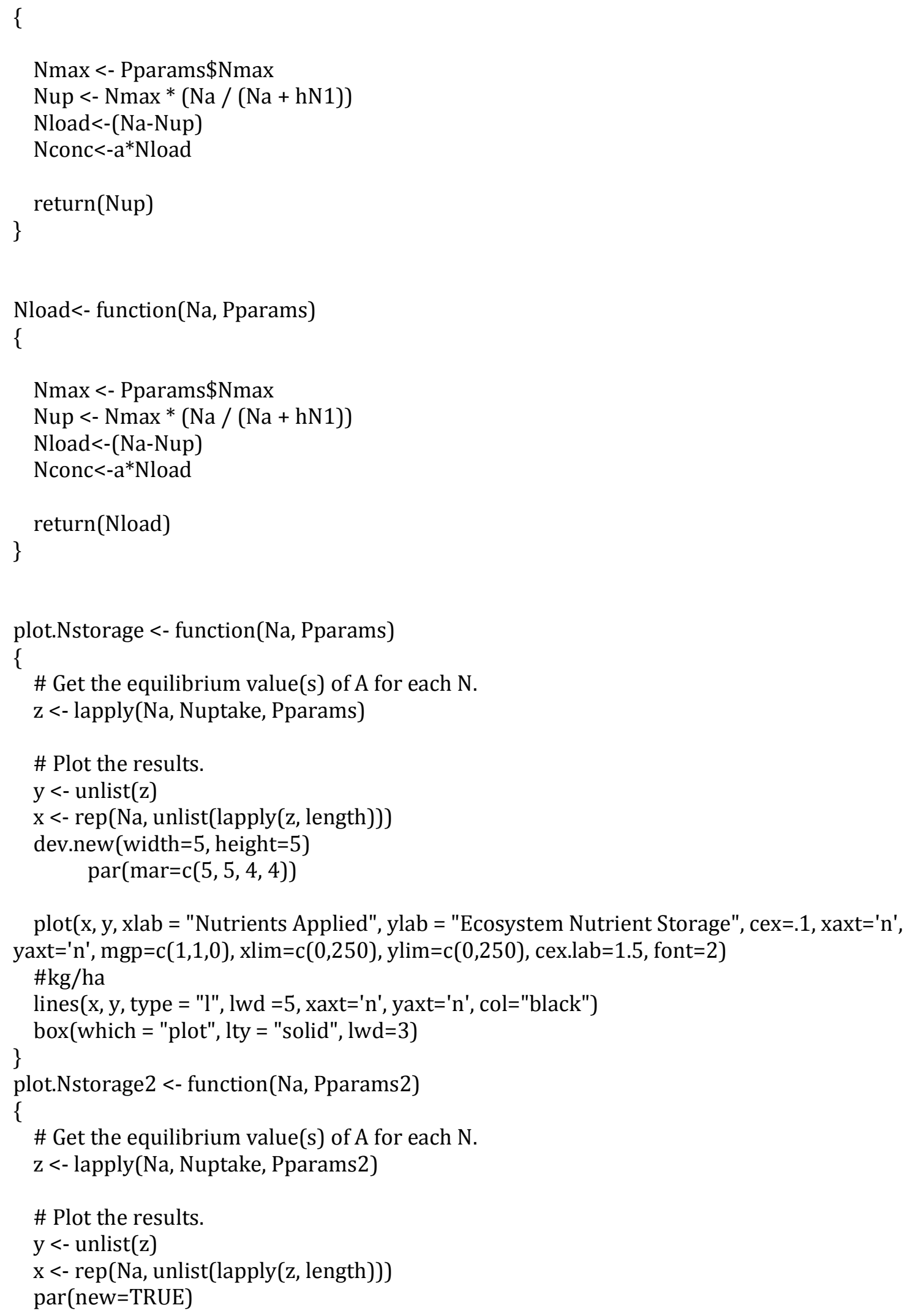




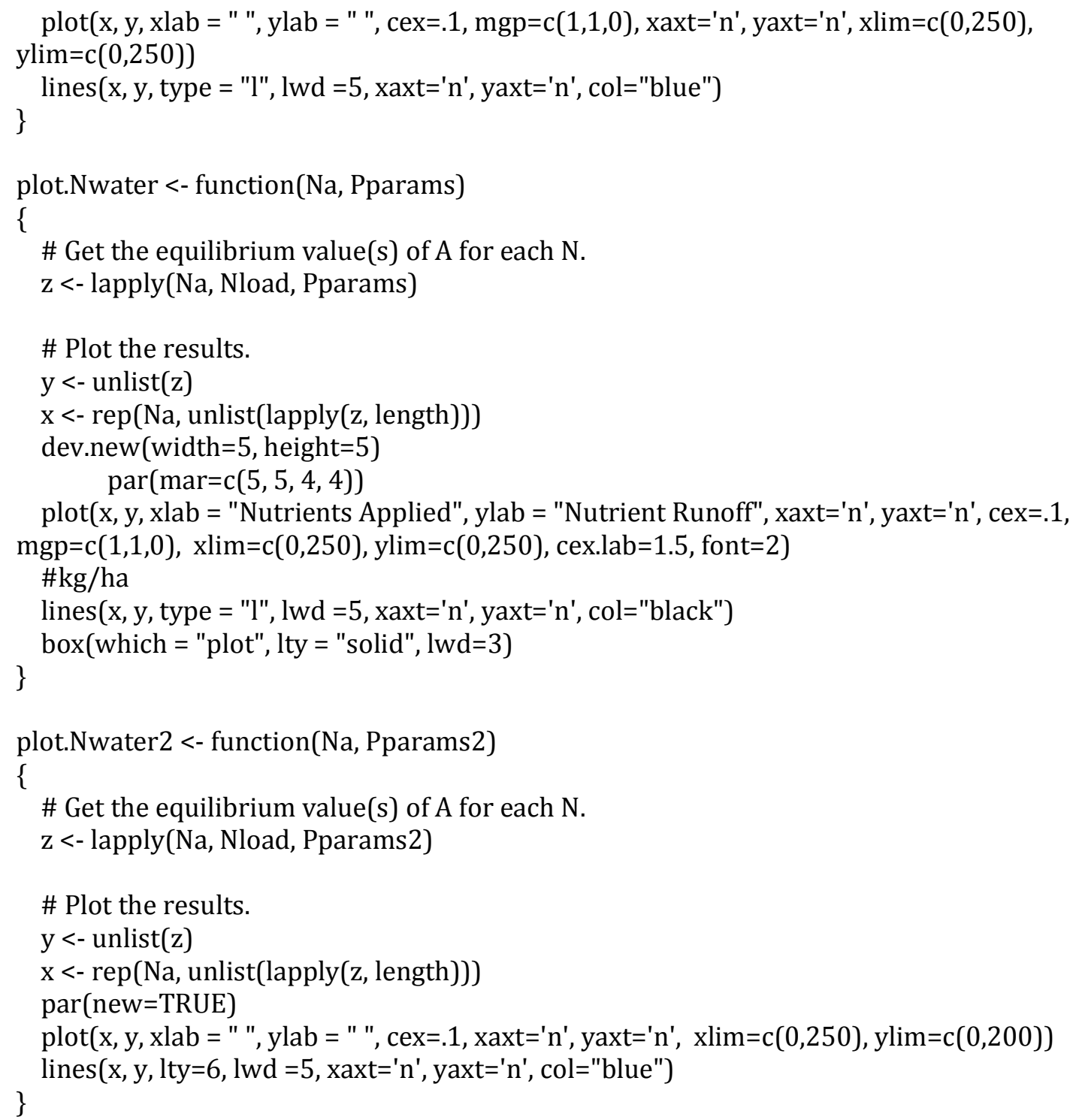


hPgood<- 30\#good technology

Nmax $<-160$

$\mathrm{hN} 1<-230$

a $<-1$

Pparams2 <- list("Pmax" = Pmax, "hP" = hP1, "Nmax"=Nmax, "hN"= hN1, "hPgood" = hPgood, "a" = a)

\# Specify the range of $\mathrm{N}$ applied $(\mathrm{Na})$ values to consider.

$\mathrm{Na}<-\operatorname{seq}(0,200$, by $=0.01)$ \#seq $(0,500$, by $=1)$

\# Get the equilibrium value(s) of A for each $\mathrm{N}$.

$\mathrm{q}<-$ lapply(Na, Nload, Pparams)

$\mathrm{t}<-$ lapply(Na, Nload, Pparams2)

$\mathrm{h}<-$ lapply(Na, Prod, Pparams)

j <- lapply(Na, goodProd, Pparams)

\# Store the results for productivity.

$\mathrm{P}<-$ unlist( $\mathrm{h}$ )

$\mathrm{J}<-$ unlist $(\mathrm{j})$

\# Store the results for water [N].

Nconc $<-$ unlist(q)

Nconc2 <-unlist(t)

$\mathrm{NP}<$-data.frame(Nconc)

$\mathrm{NP} \$ \mathrm{Na} 1<$-data.frame $(\mathrm{Na})$

NP\$Prod $<-P$

NP\$goodProd $<-$ J

NP2<-data.frame(Nconc2)

NP2 $\$ \mathrm{Na} 1<$-data.frame(Na)

NP2\$Prod $<-P$

NP2\$goodProd<-J

\#colnames(NP)<-c("Nconc","Na","Prod")

\#Nco<-data.frame $(\mathrm{Nc})$

\section{\#-}

\#\#\# This section written by Emma Goldberg

\#\#\# Scheffer et al. 1993, Box 1 \#\#\#

\#\#\# 30 July 2012 eeg@uic.edu \#\#\#

\# First, set $\mathrm{dA} / \mathrm{dt}=0$, substitute in the expression for $\mathrm{V}$, and multiply

\# everything out. The result is this expression, as long as A and $\mathrm{c}$ are not

\# zero:

$\# h V^{*} A^{\wedge}(p+1)-M^{*} A^{\wedge} p+h A^{\wedge} p *(h V+1) * A-M^{*} h A^{\wedge} p=0$

\# where $\mathrm{M}=(\mathrm{r} / \mathrm{c}) *(\mathrm{~N} /(\mathrm{N}+\mathrm{hN}))^{*} \mathrm{hV}$

\# The solution below assumes that $\mathrm{p}$ is a whole number: 0,1 , 2 , etc. 
\# Then, the expression above is a polynomial in A, and R's polyroot() function \# can be used to find the solutions.

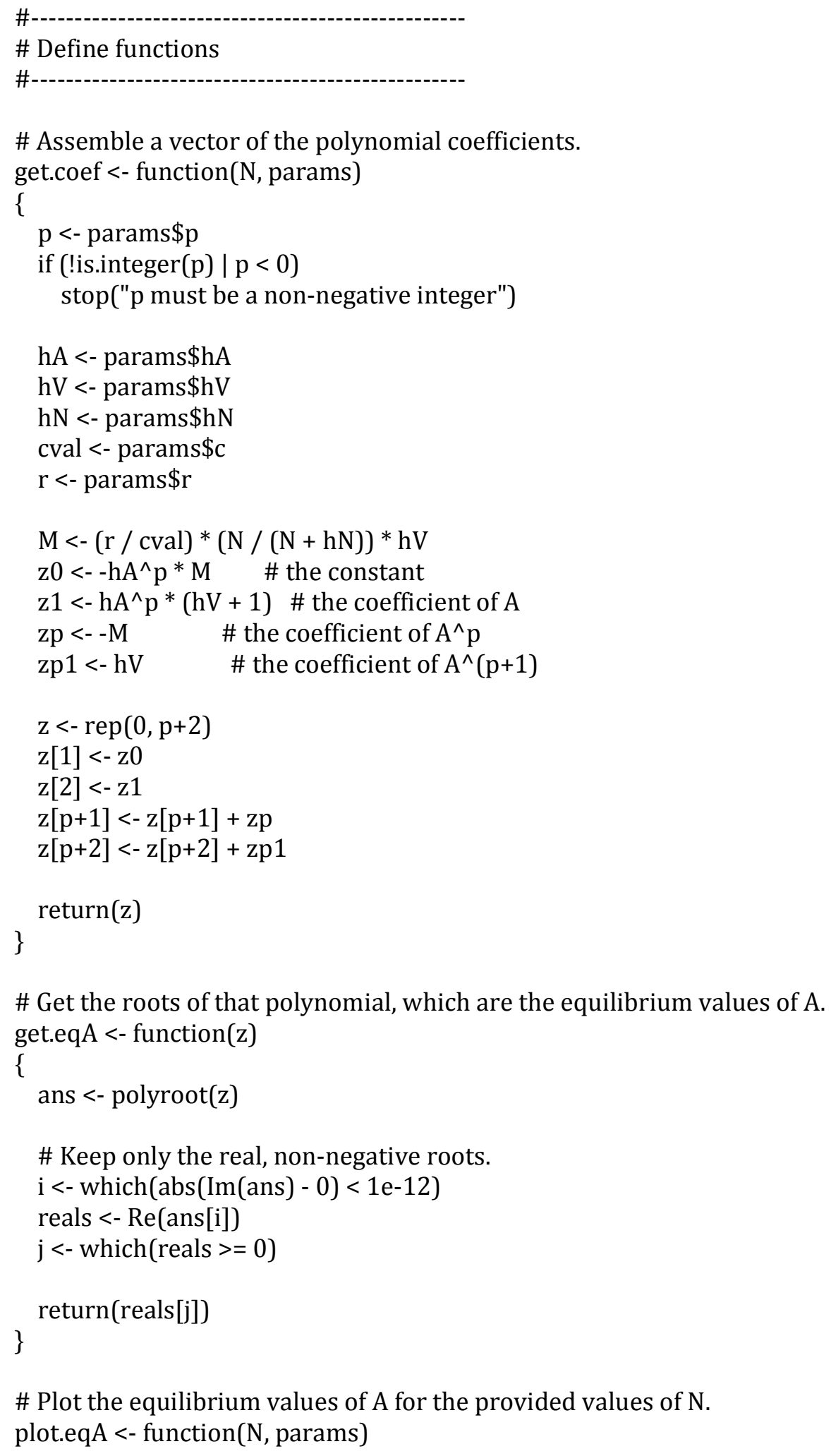

\# Plot the equilibrium values of $\mathrm{A}$ for the provided values of $\mathrm{N}$. plot.eqA $<$ - function(N, params) 


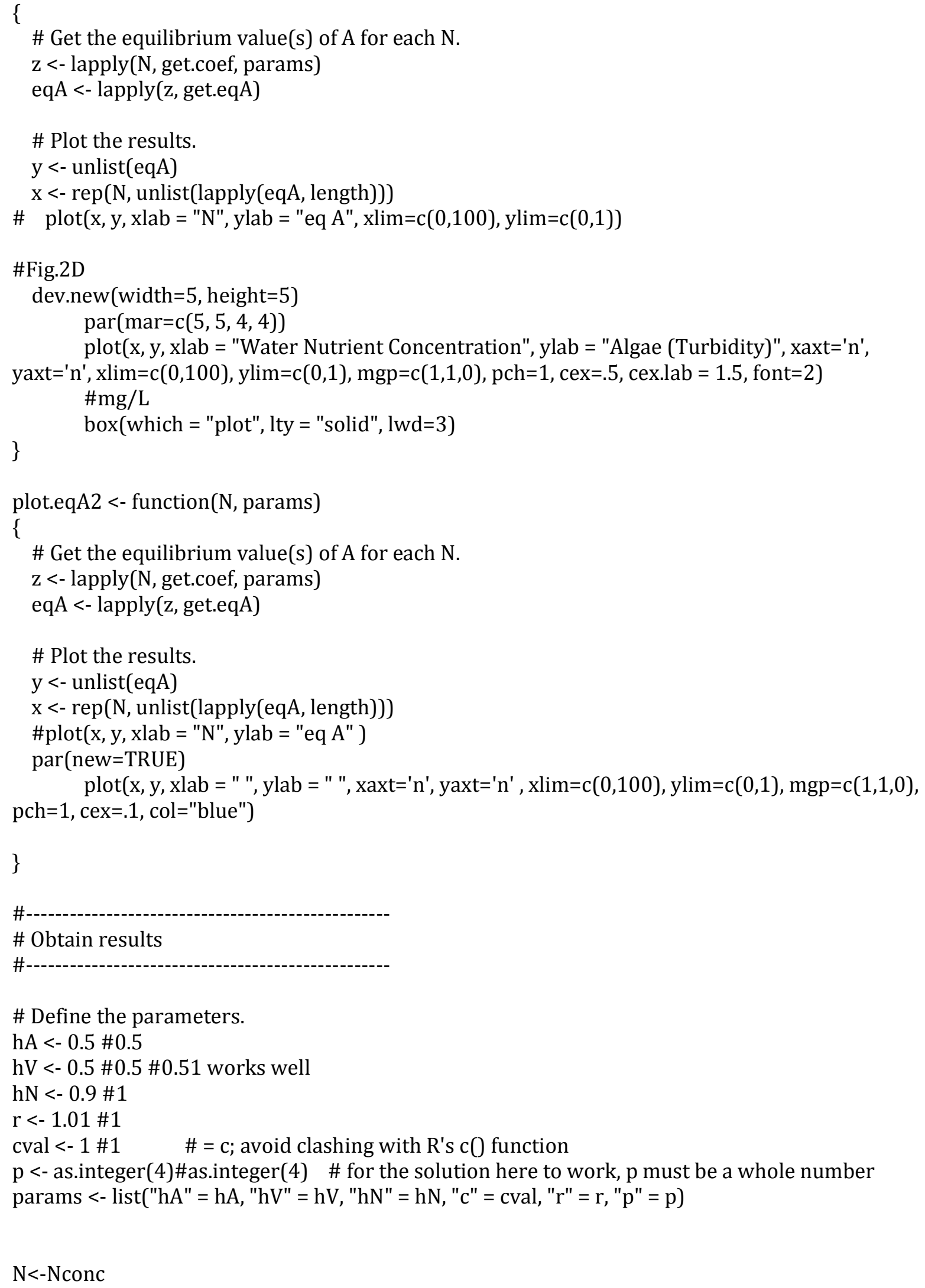


\#Fig. 2D

\# Plot the equilibrium values of $\mathrm{A}$ as a function of $\mathrm{N}$.

plot.eqA(N, params)

$\mathrm{z}<-$ lapply(N, get.coef, params)

eqA $<-\operatorname{lapply}(\mathrm{z}$, get.eqA)

$\mathrm{y}<-$ unlist(eqA)

$\mathrm{X}<-\operatorname{rep}(\mathrm{N}$, unlist(lapply(eqA, length))

\#ylim=c(0.2,0.8), $x \lim =c(1,200)$

$\mathrm{N}<-\mathrm{N}$ conc2

\# Plot the equilibrium values of $\mathrm{A}$ as a function of $\mathrm{N}$.

\#plot.eqA2(N, params)

z2 <- lapply(N, get.coef, params)

eqA $<$ - lapply(z2, get.eqA)

y2 <- unlist(eqA)

$\mathrm{x} 2<-\operatorname{rep}(\mathrm{N}$, unlist(lapply(eqA, length))

\#\#-

\#\#\#\#\#\#\#\# J. Cavender-Bares

\#Store results in matrix; matrix includes water quality as a negative linear function of algae

AN $<-\operatorname{cbind}(\mathrm{x}, \mathrm{y}, 1-\mathrm{y})$

colnames(AN)<-c("Nconc","A","W")

$\mathrm{Q}<-$ merge $(\mathrm{AN}, \mathrm{NP}$, by.x = "Nconc", by.y = "Nconc", all=TRUE)

AN2 <- $\operatorname{cbind}(\mathrm{x} 2, \mathrm{y} 2,1-\mathrm{y} 2)$

colnames(AN2)<-c("Nconc2","A2","W2")

Q2<-merge(AN2,NP2, by.x = "Nconc2", by.y = "Nconc2", all=TRUE)

\#\#graph individual relationships

\#plot(Q\$Prod, Q\$A, xlab = "Productivity (Kg m-2 y-1)", ylab = "Algae", pch=1, cex=0.1)

\#plot $(\mathrm{Q} \$$ Prod, $\mathrm{Q} \$ \mathrm{~W}, \mathrm{xlab}=$ "Productivity $(\mathrm{Kg} \mathrm{m-2} \mathrm{y-1)",} \mathrm{ylab} \mathrm{=} \mathrm{"Water} \mathrm{quality} \mathrm{services",} \mathrm{pch=1,}$ cex $=0.1$ )

\#plot $(\mathrm{Q} \$$ goodProd, $\mathrm{Q} \$ W$, xlab = "High Precision Productivity $(\mathrm{Kg} \mathrm{m}-2 \mathrm{y}-1)$ ", ylab = "Water quality services", $\mathrm{pch}=1$, $\operatorname{cex}=0.1$ ) 
\#plot(Q2\$Prod, Q2\$W, xlab = "High Precision Productivity (Kg m-2 y-1)", ylab = "Water quality services", $\mathrm{pch}=1$, $\mathrm{cex}=0.1$ )

\section{\#\#\#\#PLOT COMBINED graphs}

\section{\#\#FIGURES}

\section{\#Fig. 3A}

\# Plot the equilibrium values of $\mathrm{P}$ as a function of $\mathrm{N}$ applied.

plot.Prod(Na, Pparams)

\# Plot the equilibrium values of $\mathrm{P}$ as a function of $\mathrm{N}$ applied.

plot.goodProd(Na, Pparams)

\section{\#Fig.3B}

\# Plot the equilibrium values of $[\mathrm{N}]$ as a function of $\mathrm{N}$ applied.Bad technology plot.Nstorage(Na, Pparams)

\# Plot the equilibrium values of [N] as a function of $\mathrm{N}$ applied.Good technology plot.Nstorage2(Na, Pparams2)

\section{\#Fig. 3C}

\# Plot the equilibrium values of $[\mathrm{N}]$ as a function of $\mathrm{N}$ applied.Bad technology plot.Nwater(Na, Pparams)

\# Plot the equilibrium values of [ $\mathrm{N}]$ as a function of $\mathrm{N}$ applied.Good technology plot.Nwater2(Na, Pparams2)

\section{Fig. 3E}

\# first plot

dev.new (width $=5$, height $=5$ )

$\operatorname{par}(\operatorname{mar}=c(5,5,4,4))$

plot $(\mathrm{Q} \$$ Prod, $\mathrm{Q} \$ \mathrm{~W}, \mathrm{ylim}=\mathrm{c}(0.2,1), \mathrm{xlim}=\mathrm{c}(0,50)$, axes = FALSE, $\mathrm{xlab}=$ "Agricultural Productivity", ylab = "Water Quality", xaxt='n', yaxt='n', pch=1, mgp=c $(1,1,0), \operatorname{cex}=.5$, cex.lab $=1.5$, font=2)

box $($ which = "plot", lty = "solid", lwd=3)

\# second plot

$\operatorname{par}($ new $=$ TRUE $)$

plot(Q\$goodProd, $Q \$ W$, ylim=c(0.2,1), xlim=c $(0,50), x l a b="$ ", ylab=" ", xaxt='n', yaxt='n', pch=1, cex=.5, type $=$ "p", col="red")

\section{\# third plot}

$\operatorname{par}($ new $=$ TRUE)

plot $(Q 2 \$$ Prod, $Q 2 \$ W 2$, ylim=c(0.2,1), xlim=c $(0,50), x l a b="$ ", ylab=" ", xaxt='n', yaxt='n', pch=1, cex $=.5$, type $=$ "p", col="blue") 


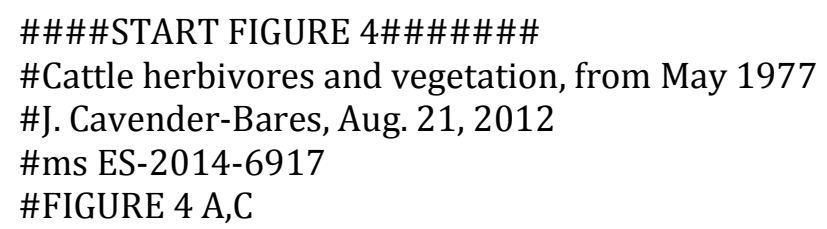




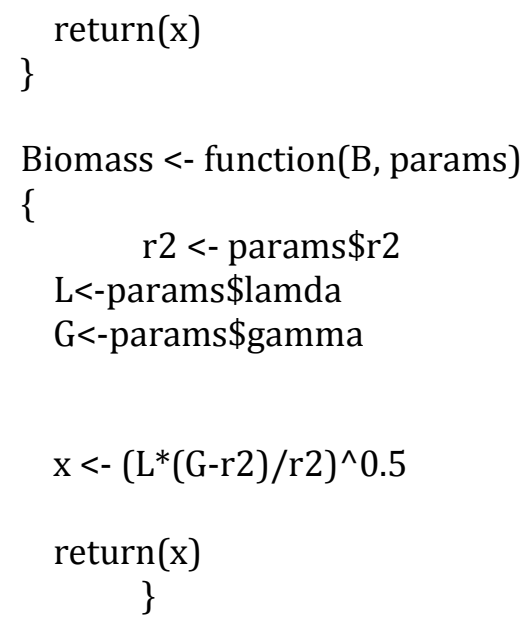




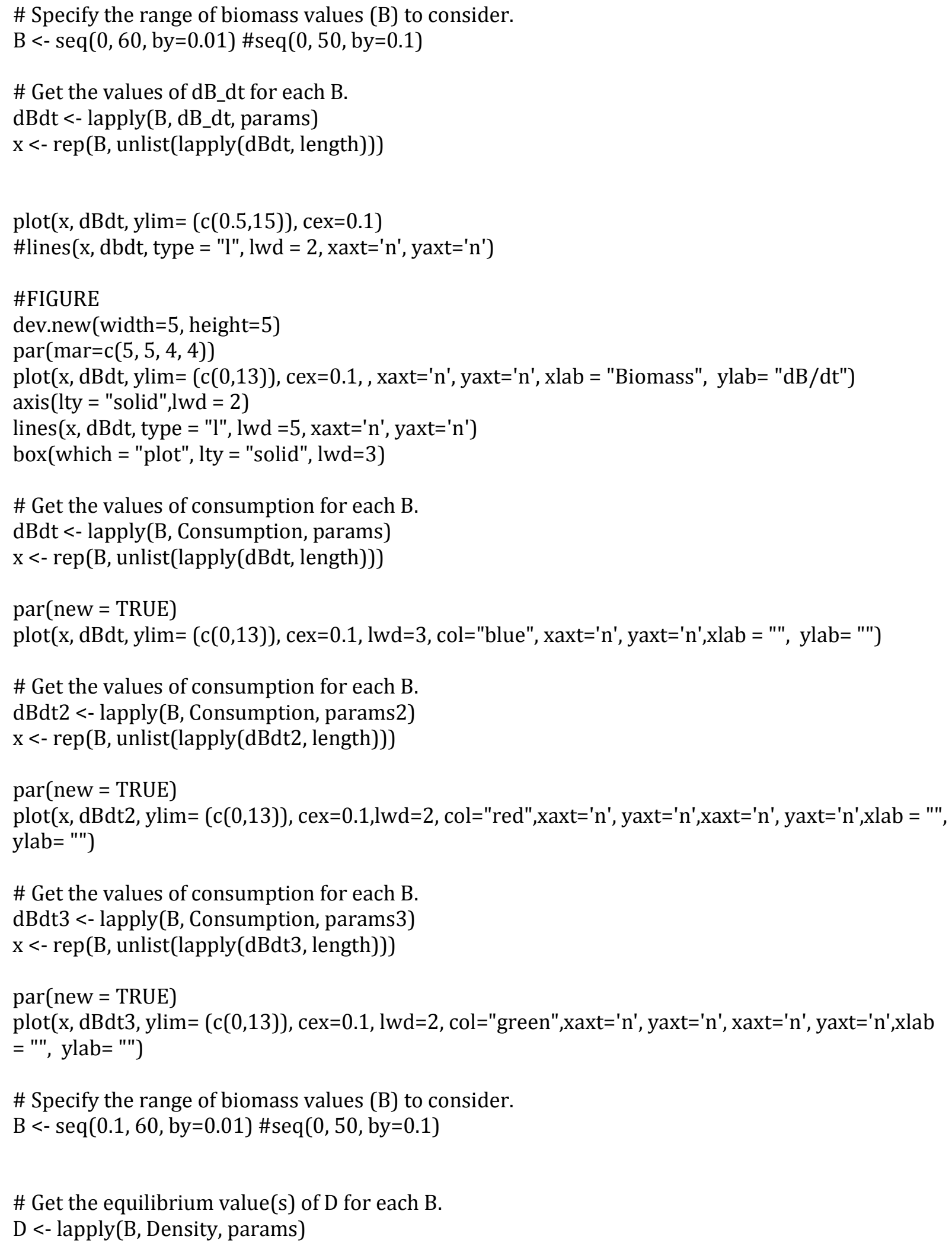


$\mathrm{z}<-\operatorname{rep}(\mathrm{B}, \mathrm{unlist}(\operatorname{lapply}(\mathrm{D}$, length)$))$

\# Store the results for density.

$\mathrm{d}<-$ unlist(D)

$\mathrm{b}<-$ unlist( $\mathrm{z}$ )

bd $<-\operatorname{cbind}(\mathrm{b}, \mathrm{d})$

colnames(bd) <- c("B", "D")

\#Graph D and B

\#Fig. 4

dev.new(width $=5$, height $=5$ )

$\operatorname{par}(\operatorname{mar}=c(5,5,4,4))$

\#xaxt='n', yaxt='n',

$\operatorname{plot}(\mathrm{D}, \mathrm{B}, \mathrm{pch}=1, \mathrm{cex}=0.1, \mathrm{xlim}=\mathrm{c}(0.5,15), \mathrm{ylim}=\mathrm{c}(-2, \max (\mathrm{B})-5), \mathrm{xlab}=$ "Cattle Density", ylab=

"Ecosystem Biomass", cex.lab = 1.5, col="gray")

lines(D, B, type = "l", lwd =5, xaxt='n', yaxt='n', col="black")

box (which = "plot", lty = "solid", lwd=3)

\#Store results in matrix;

DB <- cbind(D,B)

colnames(DB)<-c("D","B")

\#Fig. 4A

bb $<-$ lapply(B, Herbivors, params)

$\mathrm{zz}<-\operatorname{rep}(\mathrm{B}$, unlist(lapply(bb, length))

\# Results for minimum ecosystem biomass.

EB $<-$ unlist(bb)

$\mathrm{x}<-$ unlist(zz)

\#\#ADD biomass maintained by consumption.

\#xaxt='n', yaxt='n',

$\operatorname{par}($ new $=$ TRUE)

\#abline(h=max(B), col="red", lty="solid", lwd=3)

plot(x, EB, cex=0.3, xlab = " ", ylab= " ", xlim=c(0.5,15), ylim = c(-2, max(B)-5), col="red")

lines(x, EB,lwd=5, xaxt='n', yaxt='n', col="red")

\#abline(h=Bio, col="red", lty="solid", lwd=3)

\#Fig. 4B

\# Get the equilibrium values of $B$ for each D.

b3 <- lapply(B, Herbivors3, params)

z3 <- rep(B, unlist(lapply(b3, length)))

\# Results for minimum ecosystem biomass.

EB3 <- unlist(b3)

$\mathrm{x} 3<-$ unlist $(\mathrm{z} 3)$

\#FIGURE 4C 


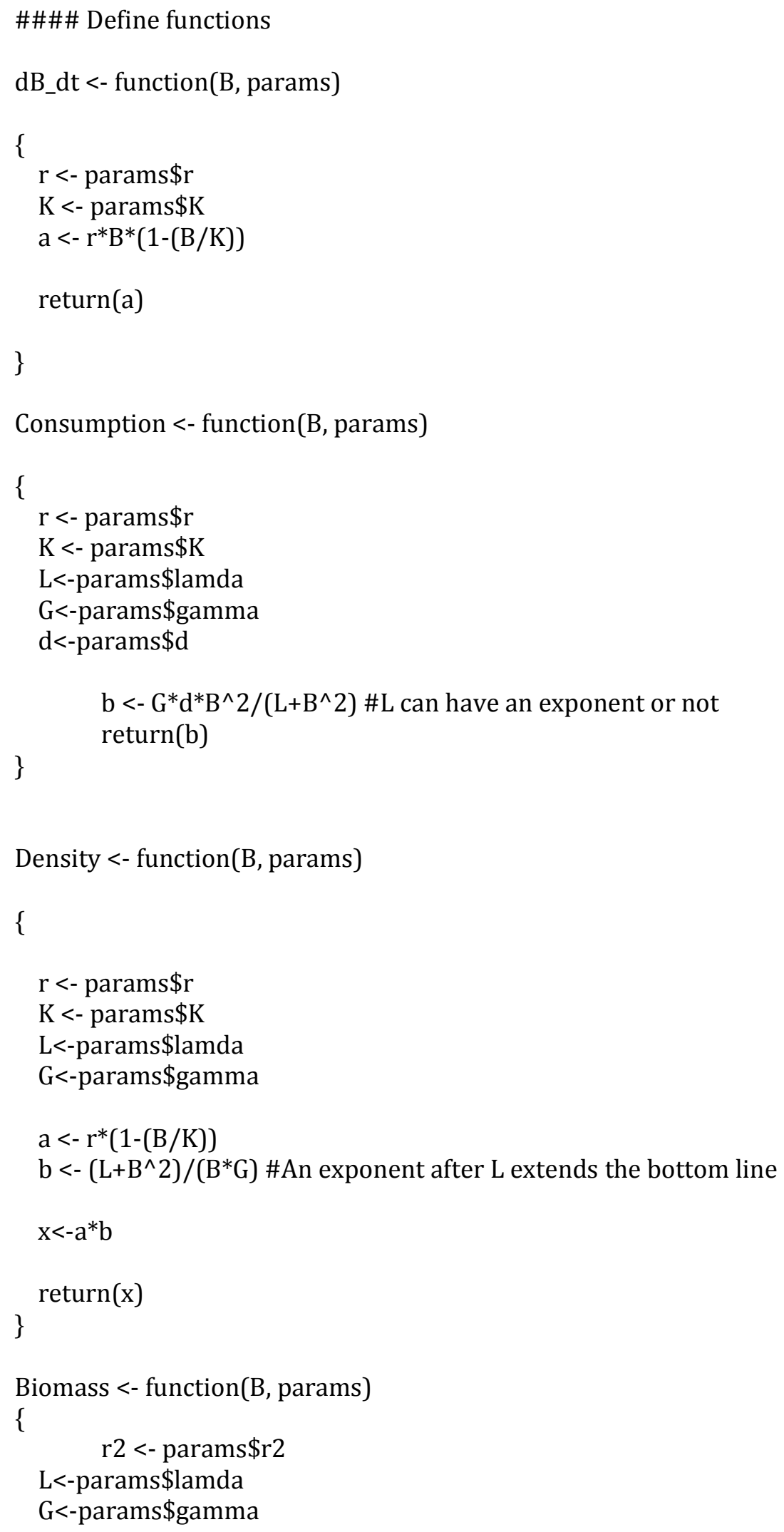




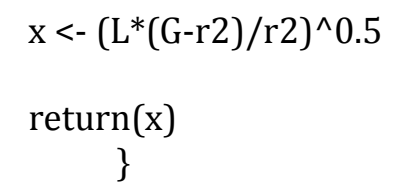

\#\#\#\# Define the parameters.

$\mathrm{r}<-1.1$

$\mathrm{r} 2<-1$

$\mathrm{K}<-50$

gamma $<-1.1$

alpha $<-0.5$

lamda $<-2$

$\mathrm{d}<-3$

$\mathrm{G}<-1.5$

$\mathrm{t}<-1$

\#change d to change consumption levels

params <- list("r" = r, "K" = K, "gamma"=gamma, "alpha"= alpha, "lamda"= lamda, "d"=d, g="g", $\mathrm{G}=" \mathrm{G} ", \mathrm{t}=$ "t") 


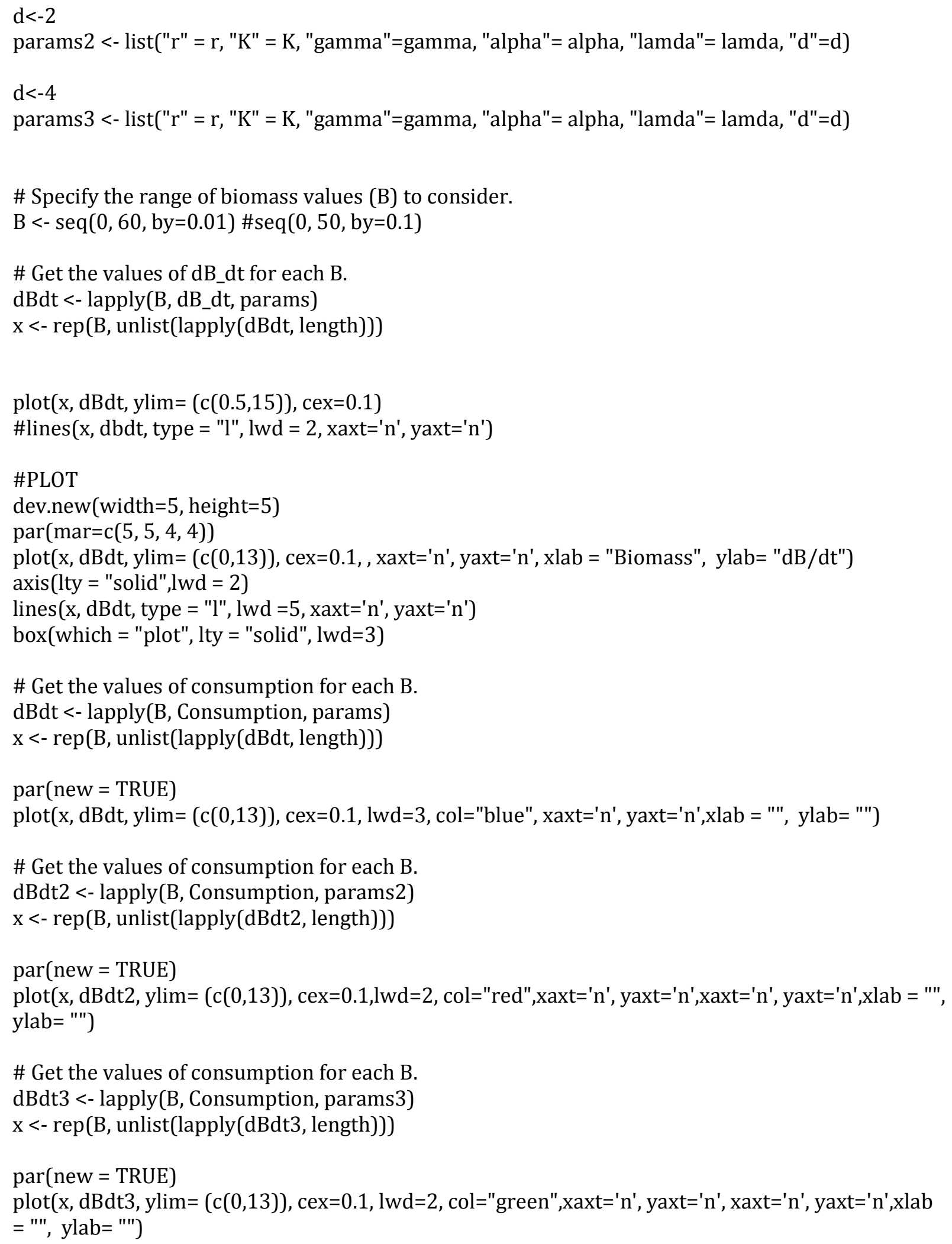


B $<-\operatorname{seq}(0.1,60$, by $=0.01) \#$ seq $(0,50$, by $=0.1)$

\# Get the equilibrium value(s) of D for each B.

D <- lapply(B, Density, params)

$\mathrm{z}<-\operatorname{rep}(\mathrm{B}$, unlist(lapply(D, length)))

\# Store the results for density.

$\mathrm{d}<-$ unlist(D)

$\mathrm{b}<-$ unlist( $\mathrm{z}$ )

bd $<-$ cbind $(b, d)$

colnames(bd) <- c("B", "D")

\#Fig. 4

dev.new(width $=5$, height $=5$ )

$\operatorname{par}(\operatorname{mar}=c(5,5,4,4))$

plot(D,B, pch=1, cex=0.1, xlim=c(0.5,15),ylim=c(-2, $\max (B)-5), x l a b=$ "Cattle Density", ylab= "Ecosystem Biomass", cex.lab = 1.5, col="gray")

lines(D, B, type = "l", lwd =5, xaxt='n', yaxt='n', col="black")

box(which = "plot", lty = "solid", lwd=3)

\#Store results in matrix;

$\mathrm{DB}<-\operatorname{cbind}(\mathrm{D}, \mathrm{B})$

colnames(DB)<-c("D","B")

\#Fig. 4A

bb $<$ - lapply(B, Herbivors, params)

$\mathrm{zz}<-\operatorname{rep}(\mathrm{B}$, unlist(lapply(bb, length))

\#Fig. 4B

\# Get the equilibrium values of $B$ for each $D$.

b3 <- lapply(B, Herbivors3, params)

z3 $<-\operatorname{rep}(B$, unlist(lapply(b3, length))

\# Results for minimum ecosystem biomass.

EB3 <- unlist(b3)

$\mathrm{x} 3<-$ unlist(z3)

\#\#ADD biomass maintained by consumption.

$\operatorname{par}($ new $=$ TRUE $)$

plot(EB3, x3, cex=0.3, xaxt='n', yaxt='n', xlab = " ", ylab= " ", xlim=c(0.5,15), ylim = c(-2, max(B)-5), col="red")

lines(EB3, x3, lwd=5, xaxt='n', yaxt='n', col="red") 
